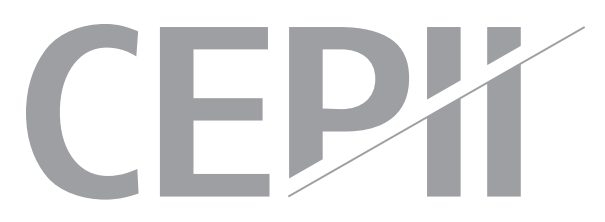

\title{
The Changing Structure of Immigration to the OECD: What Welfare Effects on Member Countries?
}

\author{
Michał Burzyński ${ }^{a}$, Frédéric Docquier ${ }^{b} \&$ Hillel Rapoport ${ }^{c}$
}

\section{Highlights}

- The skill and origin-mix of immigration to the OECD has evolved over time; especially, the last wave of immigration in the post-crisis period (2010-2015) is different in terms of skill and origin structure from the previous waves.

- We explore the welfare implication of this changing structure for native OECD citizens in terms of wages, employment, fiscal (i.e., public spending and taxes) and market size effects (i.e., the increased economies of scale and variety in consumption) brought about by immigration.

- We calibrate a general equilibrium model for 20 selected OECD member states.

- Results show that the welfare effects of immigration are very heterogeneous across skill groups, countries of destination, and immigration waves; while the last wave of immigration is less skilled and brings about lower benefits overall, the differences across immigration cohorts are small relative to the difference across receiving countries.

\footnotetext{
* We investigate the welfare implications of two pre-crisis immigration waves (1991- 2000 and 2001-2010) and of the post-crisis wave (2011-2015) for OECD native citizens. To do so, we develop a general equilibrium model that accounts for the main channels of transmission of immigration shocks - the employment and wage effects, the fiscal effect, and the market size effect - and for the interactions between them. We parameterize our model for 20 selected OECD member states. We find that the three waves induce positive effects on the real income of natives, however the size of these gains varies considerably across countries and across skill groups. In relative terms, the post-crisis wave induces smaller welfare gains compared to the previous ones. This is due to the changing origin mix of immigrants, which translates into lower levels of human capital and smaller fiscal gains. However, differences across cohorts explain a tiny fraction of the highly persistent, cross-country heterogeneity in the economic benefits from immigration. a University of Luxembourg, Luxembourg.

${ }^{b}$ FNRS and IRES, Université catholique de Louvain, Belgium.

c Paris School of Economics, Université Paris 1 Panthéon-Sorbonne and CEPII, France.
} 


\section{Abstract}

We investigate the welfare implications of two pre-crisis immigration waves (1991-2000 and 2001-2010) and of the post-crisis wave (2011-2015) for OECD native citizens. To do so, we develop a general equilibrium model that accounts for the main channels of transmission of immigration shocks - the employment and wage effects, the fiscal effect, and the market size effect - and for the interactions between them. We parameterize our model for 20 selected OECD member states. We find that the three waves induce positive effects on the real income of natives, however the size of these gains varies considerably across countries and across skill groups. In relative terms, the post-crisis wave induces smaller welfare gains compared to the previous ones. This is due to the changing origin mix of immigrants, which translates into lower levels of human capital and smaller fiscal gains. However, differences across cohorts explain a tiny fraction of the highly persistent, cross-country heterogeneity in the economic benefits from immigration.

\section{Keywords}

Immigration, Welfare, Crisis, Inequality, General Equilibrium.

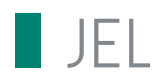

C68, F22, J24.

\section{Working Paper}

\section{CEPI}

CEPII (Centre d'Etudes Prospectives et d'Informations Internationales) is a French institute dedicated to producing independent, policyoriented economic research helpful to understand the international economic environment and challenges in the areas of trade policy, competitiveness, macroeconomics, international finance and growth
CEPII Working Paper

Contributing to research in international economics

C C CEPII, PARIS, 2018

All rights reserved. Opinions expressed in this publication are those of the author(s) alone.

$\begin{array}{ll}\text { Editorial Director: } & \text { CEPII } \\ \text { Sébastien Jean } & \text { 20, avenue de Ségur } \\ & \text { TSA 10726 } \\ \text { Production: } & 75334 \text { Paris Cedex } 07 \\ \text { Laure Boivin } & +33153685500 \\ & \text { www.cepii.fr } \\ \text { No ISSN: } 1293-2574 & \text { Press contact: presse@ }\end{array}$




\section{Introduction}

For the last 50 years or so, industrialized countries have experienced a sharp rise in the proportion of immigrants originating from developing countries. This changing national origin mix of the immigrant flow can potentially affect the labor market performance of immigrants (Borjas, 1993) or their fiscal contribution in the host country (Borjas and Trejo, 1993). In public opinions, the common portrayal of this process is a growing inflow of poorly educated immigrants trying to gain access to the labor markets and to the welfare systems of rich countries. Such inflow is usually perceived as depressing wages, causing job losses, increasing income inequality, and widening fiscal deficits. In contrast to popular perceptions, the academic literature has found little effects of immigration on fiscal deficits and on natives' labor market outcomes. Interestingly, many studies have even identified global economic gains for the host-country population. However, little is known about the evolution of these gains or about the welfare implications of the recent trend in the origin mix of immigrants. Has the economic impact of immigration deteriorated over the last 25 years? Has the post-crisis immigration wave been less beneficial or more detrimental than earlier ones? Who are the winners and losers from recent immigration? These are the questions addressed in this paper.

More precisely, we investigate the welfare effects of the post-crisis immigration wave for OECD native citizens, and compare it with two pre-crisis immigration waves. For 20 selected OECD member states, we develop a general equilibrium model that accounts for the main channels of transmission of immigration shocks. The model is parameterized to match the economic and socio-demographic characteristics of each country of the sample in the year 2010. Using data on immigration stocks by country of origin, education level, duration of stay and labor market status, we identify the size and structure of three cohorts of immigration, (i) immigrants who arrived between 1991 and 2000, (ii) those who arrived between 2001 and 2010, and (iii) those who arrived between 2011 and 2015 (referred to as the post-crisis wave). By reference to the year 2010, we then quantify how the real income of native citizens has been affected by these three immigration cohorts, distinguishing between working age natives and retirees, and between college graduates and the less educated.

Immigration affects the size of the economy as well as the composition of the population. Thanks to the development of new theoretical foundations and to the recent availability of comparative migration data, a growing consensus on how to formalize the economic responses to immigration shocks has emerged in the literature. In particular, recent studies have investigated how immigration impacts wages, employment rates and income inequality (e.g. Card, 2009; Ottaviano and Peri, 2012), taxes and public spending (e.g. Storesletten, 2000), and firms' entry and exit decisions as well as the variety of goods available to consumers (e.g. di Giovanni et al. 2015; Iranzo and Peri, 2009). Assessing the welfare impact of immigration on natives 
requires accounting for these various transmission channels and for the interactions between them. This task is performed in Aubry et al. (2016), who combine the major transmission channels of migration shocks into an integrated, multi-country model with firms and heterogeneous individuals. Their model allows to quantify the effect of each channel, to identify the dominant ones, and to compare the between- and within-country redistributive effects of immigration. Although labor market and fiscal effects are non-negligible in some countries, they conclude that an important source of gain comes from the market size effect, i.e. the change in the variety of goods available to consumers, which translates into a change in the average price index. Another related work is that of Battisti et al. (2017), who parameterize a general equilibrium model with search frictions and wage bargaining for 20 OECD economies. They also model the fiscal effect of immigration but disregard the market size mechanism.

In this paper, we depart from the model developed in Aubry et al. (2016). Contrary to them, we abstract from international trade in goods and services (which is shown to induce negligible effects on the welfare impact of immigration), but we account for changes in labor market participation and for the unemployment rates of immigrants. There are two reasons why accounting for the labor market status of immigrants might be important. Firstly, immigrants from poor countries are perceived as having smaller participation rates than natives and other immigrants; hence, the rising share of these migrants might reduce the average participation and employment rates. Secondly, economic responses to immigration are likely to be affected by the "employability" of immigrants. If employment rates are low, immigration induces less competition on the labor market, but smaller fiscal gains and smaller market size effects. We use this model to assess the welfare consequences of the changing structure of the immigrant flow 1

Overall, we find that the three immigration waves induce positive effects on the real income of natives. We find large cross-country variations in the welfare impact of immigration, but these disparities are strongly persistent across immigration waves. Countries exhibiting the largest gains are Australia, Luxembourg, the United Kingdom, Switzerland, France and Austria. These are the countries where quality-selective immigration policies are implemented, or where population aging has reached an advanced stage. In spite of these economic gains, anti-immigration sentiments are on the rise in some of these countries. The smallest gains are obtained in Scandinavian countries, Belgium, Spain and Greece. The effect of immigration on income inequality varies across countries; it can be positive or negative, depending on the educational structure of immigration. Although immigration does not adversely affect the real

\footnotetext{
${ }^{1}$ Another contribution of this paper is that we assess the sensitivity of our results to less consensual mechanisms of transmission highlighted in the recent literature, such as productivity externalities related to cultural diversity (e.g. Alesina et al., 2016; Docquier et al., 2016), to schooling (e.g. Moretti, 2004a b; Iranzo and Peri, 2009) or to the increased diffusion of productive capacity across countries (e.g. Bahar and Rapoport, 2017; Kerr, 2017). Results are provided in the Appendix.
} 
income of less educated natives, it increases the income gap with college graduates in a majority of countries (especially in Scandinavian countries, Belgium, Spain and Greece).

Turning our attention to the evolution of these gains, our analysis reveals that the changing origin mix is a good predictor of the changing educational structure of the immigrant population. This implies that the structure of dyadic migrant inflows is highly persistent over time. However, with a few exceptions, the correlation between dyadic and source-country characteristics is limited. This means that (i) the actual "education mix" of immigrant flows is affected by the origin mix through dyadic self-selection patterns, and (ii) these dyadic differences in selfselection are highly persistent across immigrant waves. They presumably vary with enduring destination characteristics such as immigration policy, geography, language, colonial ties, wage and industry structures, etc. Selection along labor market preferences is driven by a subset of these characteristics as well as by labor market institutions. As far as welfare implications are concerned, we find no evidence of systematic changes across the two pre-crisis immigration waves. On the contrary, the post-crisis wave induces smaller welfare gains compared to the earlier ones. This is because post-crisis immigrants are relatively less educated than former immigrants. They earn less and induce smaller fiscal gains. With the exception of Portugal, this result applies to all 20 OECD countries under investigation. The inequality impact has slightly intensified after the crisis, but not in all countries. These phenomena can be attributed to the combined effect of the changing origin mix and of self-selection. However, as stated above, these welfare changes induced by the origin mix are limited and much smaller than those induced by highly persistent self-selection patterns. In other words, over the last 25 years, the welfare responses to the changing origin mix have been limited.

The remainder of the paper is organized as follows. Section 2 provides stylized facts on the changing size and structure of immigration as well as on the process of migrants' self-selection. Section 3 describes the theoretical model and the calibration strategy. Quantitative results are discussed in Section 4 . Finally, Section 5 concludes.

\section{Origin mix and self-selection: stylized facts}

Immigration has become a first-order political issue in virtually all industrialized countries. This is partly due to the fact that the size and structure of immigration have considerably evolved over the last half century. This is illustrated in Figure 1, which depicts immigration trends to 20 selected OECD countries, namely the 15 members of the European Union (EU15), the US, Canada, Australia, Switzerland and Japan. Exploiting bilateral migration data from Özden et al. (2011) and from United Nations (2014), Figure 1. a shows that the share of the foreignborn population increased in all high-income countries between 1960 and 2015; on average, it increased from 4.6 to 11.0 percent ( +6.4 percentage points). Figure 1 . b shows that this change is 
totally explained by the inflow of immigrants from developing countries, whose average share in the total population increased from 1.5 to 7.9 percent (once again, +6.4 percentage points). In spite of limited differences across countries, an increasing share of the population of OECD member states is originating from countries that are economically, geographically and culturally more distant. In the US (red bold curve), the population share of immigrants from developing countries increased by $9.6 \%$ (1.3 times the change in the total immigration rate); in the EU15 (black bold curve), it increased by $7.1 \%$ ( $83 \%$ of the total change). The growth rate of the total stock of immigrants has been curbed by the recent crisis. However, the crisis has affected both inflows from rich and from poor countries.

In this context, the rising concerns about immigration are legitimate. Developing countries exhibit lower productivity levels, lower levels of human capital, and lower labor market participation rates (mostly due to lower female participation rates). The changing origin mix of immigrant flows is thus usually associated with a decrease in their average skill level, productivity, and participation rate. Figures 1.c to1. f provide the mean gaps in schooling, income, and labor market participation between origin and destination countries, as proxied by the ratio of the (weighted) mean level observed in migrants' origin countries to the mean level observed in the destination country. A ratio above 100 percent means that the average immigrant is originating from a country with more schooling, higher income per capita or higher participation rates; a ratio below 100 percent means that immigrants have observable characteristics associated with lower productivity. Between 1960 and 2015, the schooling ratio decreased in the majority of countries (except in the US, Australia, Canada, Switzerland, and to a lesser extent Japan, Belgium and Portugal). It increased from 27 to 35 in the US; it decreased from 112 to 73 in the EU15 (see Figure 1.c). Over the same period, the income ratio decreased in all countries. It declined from 50 to 26 in the US and from 66 to 46 in the EU15 (see Figure 1.d). Finally, while males' participation rates are usually greater at origin (see Figure 1 f), females' participation rates declined in virtually all countries (except in the US and in Japan). It increased from 84 to 88 in the US, and decreased from 105 to 91 in the EU15 (see Figure 1.e).

Under neutral selection, the changing origin mix of immigrant flows would result in large changes in the educational structure, productivity and labor market performance of immigrants. Natives' views reflect these presumptions. For example, the 2014 edition of the Transatlantic Trends on Immigration reveals that about 60 percent of European citizens view emigration and immigration as a problem and not as an opportunity. Such concerns are particularly important regarding immigrants from developing countries; 56 percent of Europeans expressed concerns about non-EU immigration, while only 43 percent perceive intra-EU migration as a problem. Public opinions are partly governed by non-economic reasons such as the perceived negative effects of immigration on social cohesiveness, national identity, crime, terrorism, etc. However, attitudes towards immigration are systematically correlated with two major economic concerns: 

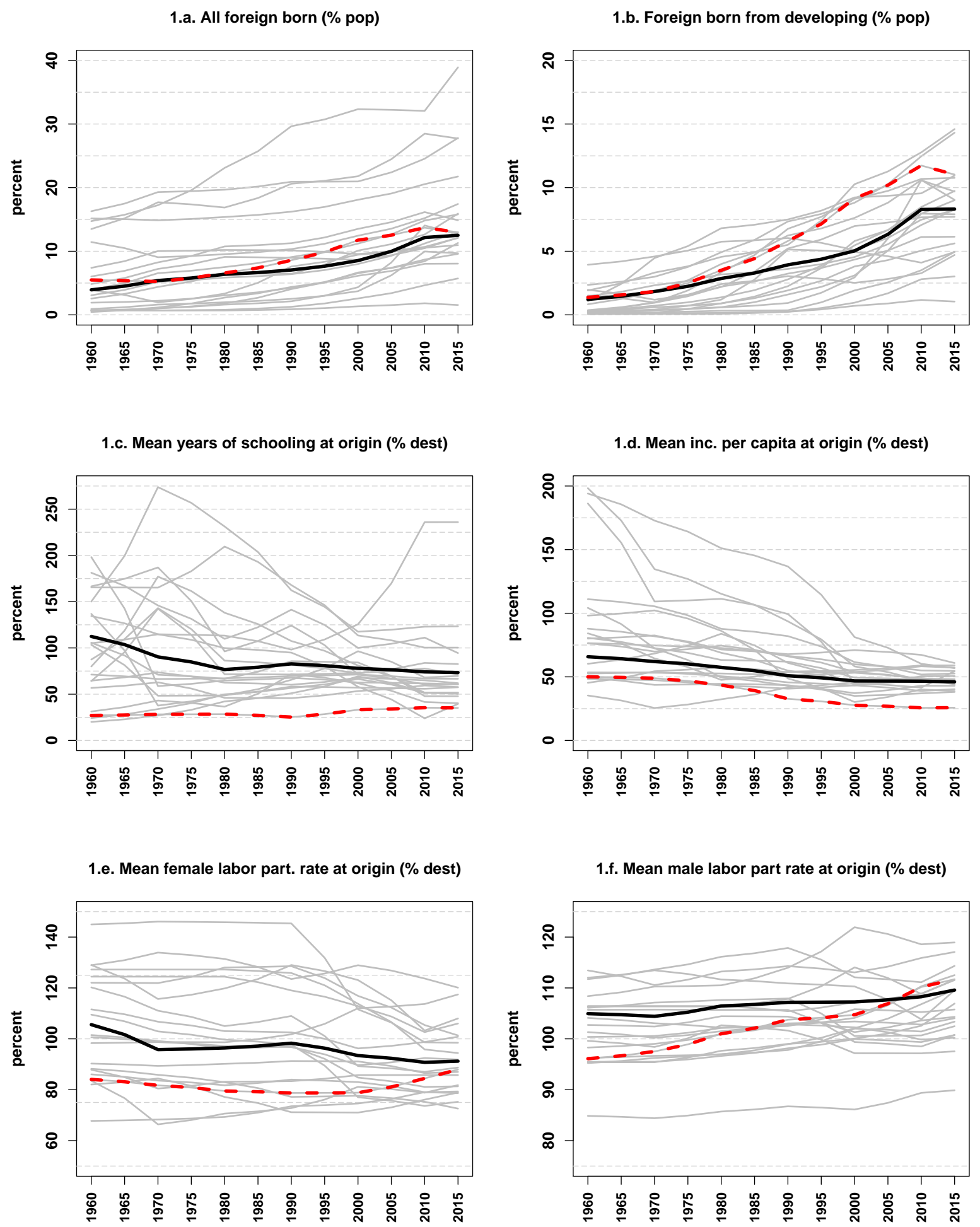

Figure 1: Changing size and origin-mix of immigrants (EU15 member states and selected OECD countries, 1960-2015)

Notes. Figure 1 shows the results for 20 selected countries: the 15 members states of the European Union (EU15), the US, Canada, Australia, Switzerland and Japan. The bold black curve represents the average of the EU15; the dotted red curve represents the US; light grey curves represent the other countries. Data in 10-year intervals from 1960 to 2010 are obtained from Özden et al. (2011); data for 1995, 2005, 2010 and 2015 are obtained from UNPOP; data for 1965, 1975, 1985 interpolate decadal observations. 
the perceived adverse labor market effects of immigration, and its fiscal effects. The European Social Survey data for the year 2014 show that only 26 percent of European respondents believe that immigrants contribute positively to public finances, and only 35.9 percent think that immigrants contribute to create new jobs for natives. ${ }^{2}$

However, these general perceptions must be tempered by the fact that migrants self-select along many attributes and partly assimilate (Abramitzky et al., 2012; Chiquiar and Hanson, 2005; McKenzie and Rapoport, 2010; Moraga, 2011; Ambrosini and Peri, 2012; Kaestner and Malamud, 2014). The degree of self-selection governs migrants' characteristics and outcomes at destination. If it is strong, the correlation between migrants' and home-country attributes becomes weak. Furthermore, if migrants select their destination country to limit the gap between their own preferences and the host-country characteristics, a positive correlation between migrants' and host-country attributes can be obtained (i.e., there is positive sorting). To illustrate the process of self-selection, we use the Database on Immigrants in OECD countries (DIOC) described in Arslan et al. (2015). The data are collected by country of destination and are mainly based on population censuses and administrative registers. The DIOC database provides detailed information on the country of origin, demographic characteristics, level of education, and labor market outcomes of the population of OECD member states..$^{3}$ Focusing on the census round 2010, we extract information about the country of origin (220 countries), age (25-64 and 65+), educational attainment (college graduates and less educated) and labor market status (employed, unemployed, inactive) of immigrants residing in the 20 selected destination countries listed above. For the 4,400 dyads of countries in the sample, Figure 2 compares the average level of education and participation rate of immigrants aged 25 and over with those of the home- and host-country.

The comparison with the home-country characteristics is illustrated in Figure 2.a to 2 d. Figure 2, a compares the dyadic and home-country shares of college-educated and shows the regression line. The slope is equal to 0.22 in the full sample of 4,400 dyads. Ranking countries by corridor size (from the 30 largest to the smallest), Figure 2.c depicts no size dependence; for all subsamples, the dyad-origin correlation varies between 0.2 and 0.3 without any clear pattern. In contrast with the origin mix hypothesis, the education levels of immigrants and those leftbehind are poorly correlated (a strong sign of self-selection). As for participation rates, Figure 2 b compares dyadic and home-country participation rates is greater for large corridors. In the full sample, the correlation is almost nil (0.01). However, Figure 2 d shows that the correlation amounts to 0.55 for the 30 to 40 largest corridors (representing 40 and $45 \%$ of the total migrant stock) and to 0.37 when considering the 50 largest corridors.

\footnotetext{
${ }^{2}$ See $h t t p: / / t r e n d s . g m f u s . o r g / t r a n s a t l a n t i c-t r e n d s /$ and http://www.europeansocialsurvey.org/.

${ }^{3}$ For the sake of comparability, the data from Özden et al. (2011) and from United Nations (2014) identify the total stock of immigrants in all destination countries, but only provide data by country of origin.
} 
The comparison between dyadic and host-country characteristics is illustrated in Figure 2 e and 2 h. Figure 2 g shows that the correlation between dyadic and host-country shares of college-educated is larger. It varies between 0.4 and 0.5 for the most important corridors, and falls to 0.25 when small corridors are included. In Figure $2 \mathrm{~h}$, the correlation in participation rates behaves similarly, it varies between 0.4 and 0.5 when considering the largest corridors, while for the whole sample it reduces to 0.25 (see Figure $2 \mathrm{f}$ ).

In sum, the origin-mix theory states that the characteristics immigrants can be predicted using the characteristics of the home country. Given the increasing share of immigrants originating from poor countries, it predicts a decline in the average economic performance of migrants at destination. Our stylized facts lead us to substantially qualify this view. Overall, the education levels of immigrants and their participation rates are more strongly correlated with the host-country characteristics than with the home-country ones. The dyad-origin correlations are greater for large corridors, but they are small for the vast majority of dyads. Quantitatively, it is thus unclear whether the changing national origin mix of immigrant flows sensibly affects the welfare responses to immigration. The responses are likely to vary across destination countries. To address this question, the next section describes a model that fully accounts for the dyadic structure of immigration. We use it to compare the welfare responses to three successive cohorts of immigrants in each of the 20 selected OECD member states in our sample.

\section{Theoretical model}

We develop a static model endogenizing the economic effect of immigration on macroeconomic variables and on the welfare of native (non-migrant) citizens. We formalize countries as independent entities, and do not account for trade linkages or capital flows between them. $4^{4}$ The country subscripts are omitted for expositional convenience. Each country is populated by heterogeneous individuals, firms that produce heterogeneous goods, and the government. As far as individuals are concerned, we distinguish between natives and immigrants, between age groups, and between two skill groups. The superscript $o$ refers to the origin country, with $o=n$ for natives and $o=f$ for foreigners. When the dyadic dimension of the data is used, we split $f$ into $f=\left(f_{1}, f_{2}, \ldots, f_{F}\right)$ for immigrants from the $F$ foreign countries. The subscript $a$ refers to the age group, with $a=y$ for working-age individuals and $a=r$ for retirees. The subscript $s$ refers to the skill group, with $s=h$ for college graduates and $s=l$ for the less educated. The

\footnotetext{
${ }^{4}$ Using a similar framework, Aubry et al. (2016) find that the welfare effect is strongly robust to the inclusion of trade. Ortega and Peri (2014) find that capital adjustments are rapid in open economies: an inflow of immigrants increases one-for-one employment and capital stocks in the short term (i.e. within one year), leaving the capital/labor ratio unchanged.
} 

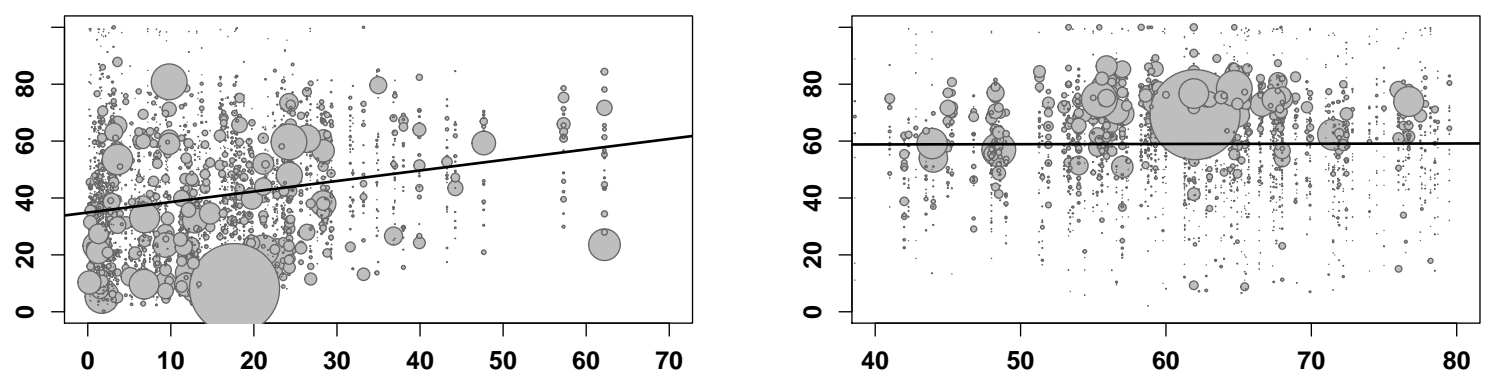

2.c. College grads (\%): B-O correlation and size
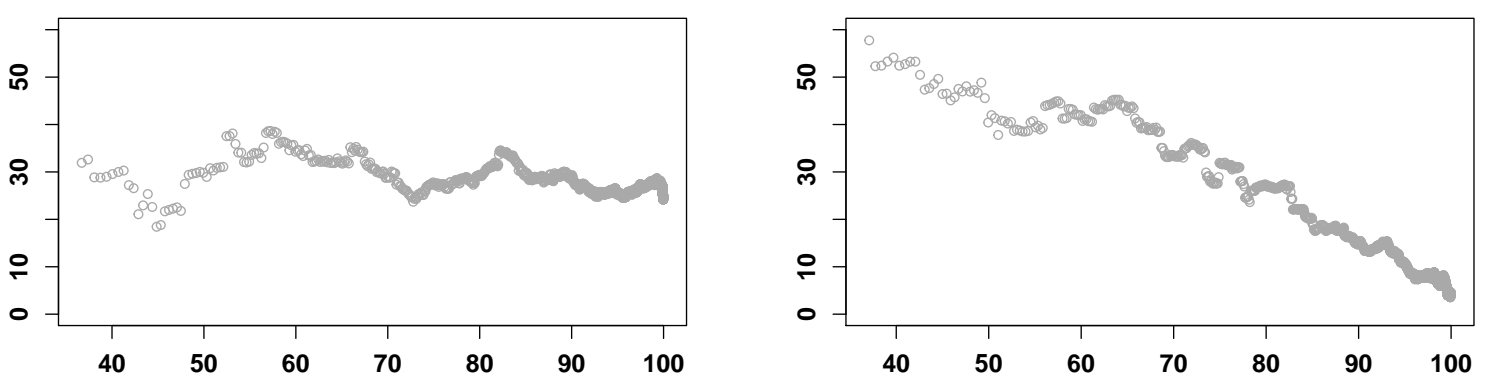

2.e. College grads (\%): bilateral vs destination (B-D)
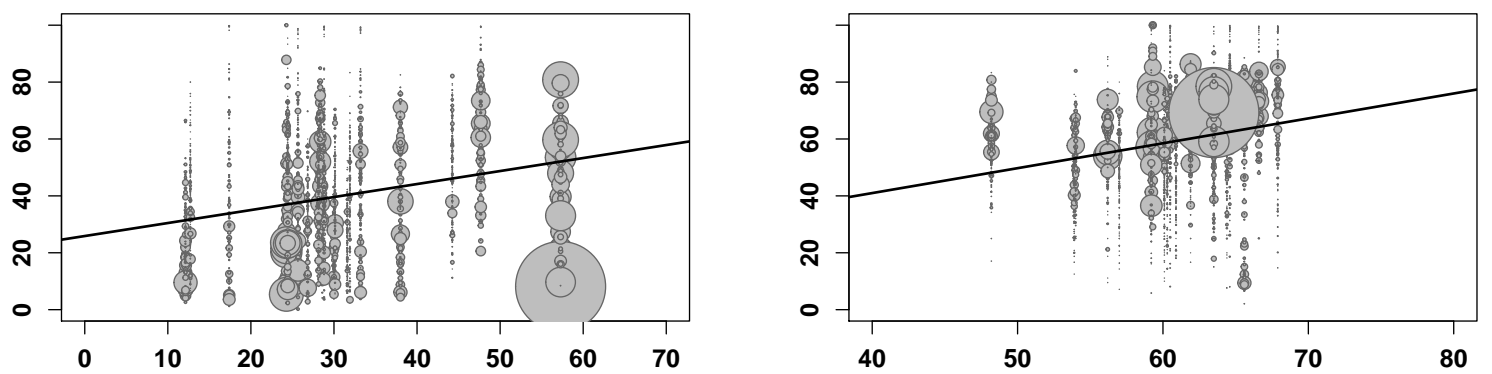

2.g. College grads (\%): B-D correlation and size

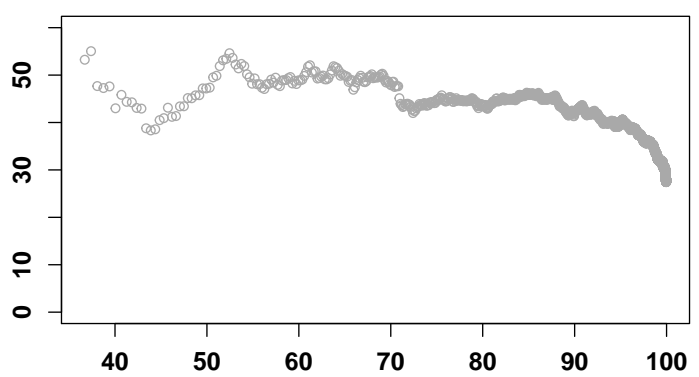

2.h. Participation (\%): B-D correlation and size

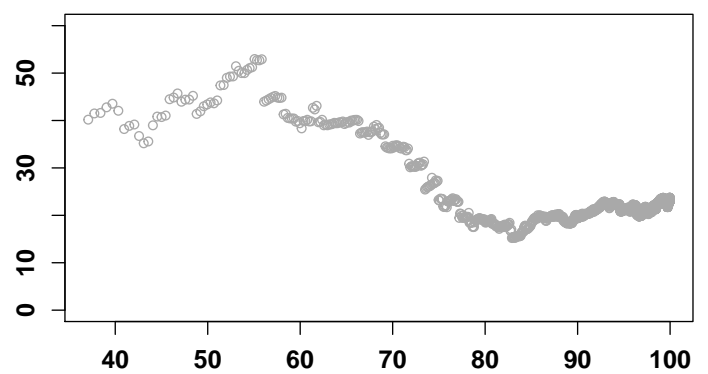

Figure 2: Migrants' selection by education and by labor market participation, 2010

Notes. Figure 2 a shows the shares of college graduates among origin-country residents (X-axis) and bilateral migrants (Y-axis); Figure 2 b shows the participation rates. We also provide the regression line. In Figures $2 \mathrm{c}$-d, dyads are ranked by descending order with respect to the migrant stock (rank $r=1$ for the largest dyad, and $r=4400$ for the smallest). We consider subsamples including the $r$ largest dyads and for $r \leq 30$ up to $r \leq 4400$, we compare the share of the total migrant stock involved (X-axis) with the correlation between bilateral and origincountry shares of college graduates and participation rates. Figure 2 e shows the shares of college graduates among host-country residents (X-axis) and bilateral migrants (Y-axis); Figure $2 \mathrm{f}$ shows the participation rates. As above, Figures 2 g-h give the correlation between bilateral and destination-country characteristics for the same subsamples for $r \leq 30$ up to $r \leq 400$. Data are obtained from the DIOC database for the year 2010 . 
demographic size of these groups is denoted by $N_{a, s}^{o}$ and is assumed to be exogenous ${ }_{5}^{5}$ As far as firms are concerned, there is a mass $B$ of firms that operate on a monopolistically competitive market with a fixed cost of entry, each of them produces a differentiated good. The government taxes income and consumption to finance redistributive transfers, unemployment benefits and public consumption.

In line with the recent literature, four channels of transmission of immigration shocks are taken into consideration in the benchmark model: the employment effect, the wage effect, the fiscal effect, and the market size effect. Additional and less consensual channels are investigated in the robustness analysis in the Appendix. We model the labor market effects as in Ottaviano and Peri (2012), the fiscal effect as in Storesletten (2000), the market-size effect as in Krugman (1980). We account for the age structure of immigration to match the fiscal features of each economy. In addition, we account for the difference in employment rates between immigrants and natives by introducing heterogeneity in the disutility of labor and in unemployment rates. Note that these could as well reflect differential access to jobs due to discrimination. The data reveal that differences in employment rates are mainly governed by differences in participation rates. This motivates our choice to endogenize participation rates and to assume, for simplicity, that active workers spend an exogenous fraction of their active time in unemployment (due, for example, to exogenous job destruction and finding rates) ${ }^{6}$ Accounting for immigrants' employment is important as it governs the intensity of the competition with natives on the labor market and well as the size of fiscal and market size effects.

In this section, we describe the preferences and the technology used to endogenize individuals' and firms' decisions in Sections 3.1 and 3.2. We then characterize the monopolistically competitive equilibrium in Section 3.4. Finally, we explain our parameterization strategy in Section 3.5 .

\subsection{Individuals}

The preferences of a representative individual in the age group $a=(y, r)$, of education level $s=(h, l)$ and from origin country $o=(n, f)$ are described by the following utility function:

$$
\mathcal{U}_{a, s}^{o}=C_{a, s}^{o}-\frac{\phi_{a, s}^{o}\left(1-\gamma_{a, s}^{o}\right)^{1+\eta}}{1+\eta}
$$

\footnotetext{
${ }^{5}$ In the real world, the population structure in general, and immigration rates in particular, depend on the state of the economy. As we are interested in the "causal" impact of immigration on the welfare of natives, our strategy consists of (i) endogenizing the state of the economy as a function of the size and structure of immigration, (ii) calibrating our model using observed immigration data, and (iii) using counterfactual no-immigration scenarios to quantify the welfare impact of immigration.

${ }^{6}$ Note that Battisti et al. (2017) use a different model with exogenous participation rates and endogenous unemployment rates. In the sensitivity analysis in Appendix, we show that our results are robust to alternative unemployment assumptions.
} 
Utility is a linear function of a composite consumption aggregate, $C_{a, s}^{o}$ (discussed below) and depends negatively on the endogenous amount of time spent on the labor market, $1-\gamma_{a, s}^{o}$. Hence, the supply of labor in the group $(o, a, s)$ is defined as $\left(1-\gamma_{a, s}^{o}\right) N_{a, s}^{o}$. The parameter $\eta$ is the inverse of the elasticity of labor supply to labor income; it is common to all individuals. The parameter $\phi_{a, s}^{o}$ captures the disutility of participating in the labor market (i.e. disutility of working or of searching for a job). It varies by age group, by education level and by country of origin. We assume $\phi_{r, s}^{o}=\infty$ for all retirees, implying that retirees are inactive and only consume the transfers received from the government. As far as working age individuals are concerned, we calibrate $\phi_{y, s}^{o}$ so as to match the observed participation rate in ech dyadic group. Hence, the model allows to capture differences in participation rate across skill groups and across natives and immigrants from a specific origin country; these differences are assumed to be due to the heterogeneity in cultural traits or social norms between countries, and to the cultural selection of immigrants.

In addition, we assume that consumers have a preference for variety. This means that the utility from consumption does not only depend on the quantity of goods consumed; it also increases with the variety of goods. Remember there is a mass $B$ of varieties available for consumption. Following Krugman (1980), the utility of consumption is described by a CES utility function over the continuum of varieties:

$$
C_{a, s}^{o}=\left[\int_{0}^{B} c_{a, s}^{o}(i)^{\frac{\epsilon-1}{\epsilon}} d i\right]^{\frac{\epsilon}{\epsilon-1}}
$$

where $c_{a, s}^{o}(i)$ stands for the quantity of variety $i \in[0, B]$ produced in the country and consumed by an individual of type $(a, o, s)$. Varieties are imperfect substitutes, characterized by a constant elasticity of substitution equal to $\epsilon>1$.

In each destination country, working age immigrants in a given skill group are perfectly substitutable workers from the firm's perspective. They have identical marginal productivity levels and earn identical wages per hour worked, $w_{s}^{f}, \forall f=\left(f_{1}, f_{2}, \ldots, f_{F}\right)$, which usually differs from the native's wage rate, $w_{s}^{n}$. At each moment in time, active workers face exogenous job separation and finding rates, implying that they spend an exogenous fraction $1-u_{s}^{o}$ of their active time in employment, and the remaining fraction $u_{s}^{o}$ in unemployment (searching for a job). Working and searching induce the same disutility. Job separation and finding rates differ across natives and immigrants, but are homogeneous among immigrants (i.e., $u_{s}^{f}, \forall f=$ $\left\{f_{1}, f_{2}, \ldots, f_{F}\right\}$, and $u_{s}^{n}$ for natives). During each unemployment spell, active workers receive unemployment benefits, $b_{s}^{o}$, that are assumed to be proportional to their wage rate. We write $b_{s}^{o}=$ $\delta w_{s}^{o}$ where $\delta$ captures the replacement rate of the national unemployment insurance scheme. Finally, the government allocates group-specific transfers to each group of individuals, $T_{a, s}^{o}$, that do not depend on the labor market status. In practice, $T_{a, s}^{o}$ includes redistributive transfers 
that vary across origin and skill types, as well as public consumption which is assumed to be identical across all individuals (including retirees). Labor income is taxed at a flat rate $\tau$, while consumption is taxed at a flat rate $v$.

The individual budget constraint can be written as following:

$$
\begin{aligned}
\int_{0}^{B} c_{a, s}^{o}(i)(1+v) p(i) d i & =\left(1-\gamma_{a, s}^{o}\right)\left[\left(1-u_{s}^{o}\right) w_{s}^{o}(1-\tau)+u_{s}^{o} b_{s}^{o}\right]+T_{a, s}^{o} \\
(1+v) P C_{a, s}^{o} & =\left(1-\gamma_{a, s}^{o}\right) \varpi_{s}^{o}+T_{a, s}^{o}
\end{aligned}
$$

where $p(i)$ measures the price of variety $i, P$ stands for the ideal price index (capturing the average price per unit of the optimal consumption bundle), and $\varpi_{a, s}^{o}$ measures the nominal income per active hour, i.e. per hour supplied on the labor market (a weighted average of net wages and unemployment benefits: $\left.\varpi_{s}^{o} \equiv w_{s}^{o}\left[\left(1-u_{s}^{o}\right)(1-\tau)+u_{s}^{o} \delta\right]\right)$.

The individual's optimization problem consists in maximizing (1) subject to (2) and (3). The solution of this problem can be expressed as following:

$$
\begin{aligned}
1-\gamma_{a, s}^{o} & =\left(\frac{\varpi_{s}^{o}}{\phi_{a, s}^{o}(1+v) P}\right)^{1 / \eta} \\
C_{a, s}^{o} & =\phi_{a, s}^{o}\left(\frac{\varpi_{s}^{o}}{\phi_{a, s}^{o}(1+v) P}\right)^{\frac{1+\eta}{\eta}}+\frac{T_{a, s}^{o}}{(1+v) P} \\
\mathcal{U}_{a, s}^{o} & =\frac{\eta C_{a, s}^{o}}{1+\eta}+\frac{T_{a, s}^{o}}{(1+\eta)(1+v) P} .
\end{aligned}
$$

Clearly, the labor market participation rate increases with the real income per active hour, $\varpi_{s}^{o} / P$, and decreases with the disutility of labor, $\phi_{a, s}^{o} ; 1 / \eta$ is the elasticity of labor supply to real income per active hour. If $\delta<1-\tau$, expected unemployment spells reduce the expected income of active individuals $\left(\partial \varpi_{s}^{o} / \partial u_{s}^{o}<0\right)$, implying that the participation rate is a decreasing function of the expected unemployment rate. As firms use the same technology and preferences over varieties are symmetric, firms adopt the same pricing rule $(p(i)=p, \forall i)$ and the ideal price index equals $P=p(i) B^{-1 /(\epsilon-1)}$. Given $\epsilon>1$, this implies that an increase in the number of varieties available to consumers reduces the ideal price index, due to increased competition between monopolistic manufacturers. The comparative study of Evers and De Mooij (2008) reveals that the elasticity of labor supply to income is small (i.e., $\eta$ is large). Hence, the utility level $\mathcal{U}_{a, s}^{o}$ in (6) is almost equal to the net-of-tax, real income level $C_{a, s}^{o}$. In the quantitative analysis, we proxy welfare with the real income of people.

The mapping between bilateral and destination notations is straightforward. In equilibrium, 
the total employment of college-educated and less educated natives is defined as:

$$
\begin{aligned}
H^{n} & \equiv\left(1-u_{h}^{n}\right) N_{y, h}^{n}\left(1-\gamma_{y, h}^{n}\right), \\
L^{n} & \equiv\left(1-u_{l}^{n}\right) N_{y, l}^{n}\left(1-\gamma_{y, l}^{n}\right) .
\end{aligned}
$$

Symmetrically, the total employment of college-educated and less educated immigrants is defined as:

$$
\begin{aligned}
H^{f} & \equiv \sum_{o=f_{1}}^{f_{F}}\left(1-u_{h}^{f}\right) N_{y, h}^{o}\left(1-\gamma_{y, h}^{o}\right), \\
L^{f} & \equiv \sum_{o=f_{1}}^{f_{F}}\left(1-u_{l}^{f}\right) N_{y, l}^{o}\left(1-\gamma_{y, l}^{o}\right) .
\end{aligned}
$$

\subsection{Firms}

There is a continuum of firms with a measure $B$ producing differentiated consumption goods indexed by $i$. Each monopolistic manufacturer $i$ is characterized by the same technology, adopts the same pricing rule, employs the same number of employees, offers the same wage rates to its employees, and produces the same quantity of goods, $y(i)$. Hence, the total GDP in the economy amounts to $Y=B y(i)$.

At the firm level, the production technology is described by a nested constant elasticity of substitution (CES) function. The upper-level production function can be written as:

$$
y(i)=A q(i)=A\left[\theta_{1} h(i)^{\left(\sigma_{1}-1\right) / \sigma_{1}}+\left(1-\theta_{1}\right) \ell(i)^{\left(\sigma_{1}-1\right) / \sigma_{1}}\right]^{\sigma_{1} /\left(\sigma_{1}-1\right)},
$$

where the scale factor $A$ stands for total factor productivity (TFP), and $q(i)$ is the quantity of efficiency units of labor used by firm $i$. Labor in efficiency unit $q(i)$ is a CES function of $h(i)$ and $\ell(i)$, which stand for the composite quantity of college-educated and less educated workers employed by firm $i ; \sigma_{1}$ measures the elasticity of substitution between skill groups; and $\theta_{1}$ determines the relative productivity of college graduates compared to the less educated.

To capture the imperfect substitution between immigrants and natives, we assume that $h(i)$ and $\ell(i)$ are governed by a lower-level, nested CES production technology (as in Card, 2009, Docquier et al., 2014; Ottaviano and Peri, 2012):

$$
\begin{aligned}
h(i) & =\left[\theta_{2} h^{n}(i)^{\left(\sigma_{2}-1\right) / \sigma_{2}}+\left(1-\theta_{2}\right) h^{f}(i)^{\left(\sigma_{2}-1\right) / \sigma_{2}}\right]^{\sigma_{2} /\left(\sigma_{2}-1\right)}, \\
\ell(i) & =\left[\theta_{2} \ell^{n}(i)^{\left(\sigma_{2}-1\right) / \sigma_{2}}+\left(1-\theta_{2}\right) \ell^{f}(i)^{\left(\sigma_{2}-1\right) / \sigma_{2}}\right]^{\sigma_{2} /\left(\sigma_{2}-1\right)}
\end{aligned}
$$

where $\sigma_{2}$ measures the elasticity of substitution between immigrant and native workers within 
each skill group, and $\theta_{2}$ determines the relative productivity of native workers compared to immigrants. As stated above, immigrants from all origin countries are treated as perfect substitutes from the employer's perspective.

Firms maximize their profits. Given their market power, their optimal price is equal to a constant markup over the marginal cost of employing one unit of efficient labor: $p=\frac{\epsilon}{\epsilon-1} \frac{\bar{w}}{A}$, where $\bar{w}$ in the numerator is a wage composite related to the nested CES production function (the price of one efficiency unit of labor) defined as:

$$
\begin{aligned}
\bar{w} & =\left[\theta_{1}^{\sigma_{1}} \bar{w}_{h}^{1-\sigma_{1}}+\left(1-\theta_{1}\right)^{\sigma_{1}} \bar{w}_{l}^{1-\sigma_{1}}\right]^{1 /\left(1-\sigma_{1}\right)} \\
\bar{w}_{s} & =\left[\theta_{2}^{\sigma_{2}}\left(w_{s}^{n}\right)^{1-\sigma_{2}}+\left(1-\theta_{2}\right)^{\sigma_{2}}\left(w_{s}^{f}\right)^{1-\sigma_{2}}\right]^{1 /\left(1-\sigma_{2}\right)}, \text { for } s=(h, l) .
\end{aligned}
$$

The optimal employment levels are such that the marginal value of employee equals the nominal wage rate for each type of workers. These optimal employment levels $\left\{h^{n}(i), \ell^{n}(i), h^{f}(i), \ell^{f}(i)\right\}$ solve the following system:

$$
\begin{aligned}
w_{h}^{n} & =\left(\frac{q(i)}{h^{n}(i)}\right)^{1 / \sigma_{2}}\left(\frac{\theta_{1} \bar{w}}{\bar{w}_{h}}\right)^{\sigma_{1} / \sigma_{2}} \theta_{2} \bar{w}_{h}, \\
w_{l}^{n} & =\left(\frac{q(i)}{\ell^{n}(i)}\right)^{1 / \sigma_{2}}\left(\frac{\left(1-\theta_{1}\right) \bar{w}}{\bar{w}_{l}}\right)^{\sigma_{1} / \sigma_{2}} \theta_{2} \bar{w}_{l}, \\
w_{l}^{f} & =\left(\frac{q(i)}{\ell^{f}(i)}\right)^{1 / \sigma_{2}}\left(\frac{\left(1-\theta_{1}\right) \bar{w}}{\bar{w}_{l}}\right)^{\sigma_{1} / \sigma_{2}}\left(1-\theta_{2}\right) \bar{w}_{l}, \\
w_{f}^{h} & =\left(\frac{q(i)}{h^{f}(i)}\right)^{1 / \sigma_{2}}\left(\frac{\theta_{1} \bar{w}}{\bar{w}_{h}}\right)^{\sigma_{1} / \sigma_{2}}\left(1-\theta_{2}\right) \bar{w}_{h} .
\end{aligned}
$$

Profits are decreasing with the number of firms: $\frac{1}{\epsilon}\left(\frac{p}{P}\right)^{1-\epsilon} \bar{w} Q=\frac{\bar{w} Q}{B \epsilon}$, where $Q$ is the aggregate quantity of efficiency units of labor available in the economy, $Q=B q(i)$; $Q$ is given by the nested CES combination of the four types of workers employed in the economy. However, each firm faces a fixed entry cost, $\psi$, to enter the domestic market. This fixed costs is expressed in units of efficient labor composite, and is interpreted as an investment that a firm must make to explore the market and differentiate its product. Therefore, the aggregated demand for labor also includes the demand for workers employed for investment purposes. In a free entry equilibrium, operational profits are zeroed by the entry of new firms $\left(\frac{\bar{w} Q}{B \epsilon}-\psi \bar{w}=0\right)$, so that there is no incentive to start up a business for potential entrants. In line with Krugman (1980), the zeroprofit condition defines $B$, the equilibrium mass of manufacturers operating in the economy:

$$
B=\frac{Q}{\epsilon \psi}
$$




\subsection{Government}

The fiscal policy consists of two tax rates (the consumption tax rate $v$ and and a labor income tax rate $\tau$ ), a vector $T_{a, s}^{o}$ of group-specific transfers that includes redistributive transfers and public consumption, and the unemployment insurance scheme allocating a fraction $\delta$ of the wage rate to each unemployed active individual. Our fiscal bloc is a static version of Storesletten (2000), except that we do not link transfers to wages and we rule out budget deficits. Hence, the government budget constraint can be written as:

$$
(v+\tau) Y=\delta \sum_{o, a, s} N_{a, s}^{o}\left(1-\gamma_{a, s}^{o}\right) u_{s}^{o} w_{s}^{o}+\sum_{o, a, s} N_{a, s}^{o} T_{a, s}^{o}
$$

On the revenue side, total production is equal to total consumption; consumption and income tax revenues are proportional to $Y$. The mix between the consumption and income tax rates only induces redistributive effects: a greater income tax rates means greater transfers from working age individuals to retirees. On the expenditure side, unemployment benefits are proportional to the foregone labor income of unemployed active individuals, while transfers and public consumption are exogenous. Transfers differ across natives and immigrants but not across immigrants from different origin countries (i.e., $T_{a, s}^{f} \forall f=\left\{f_{1}, f_{2}, \ldots, f_{F}\right\}$ and $T_{a, s}^{n}$ for natives). As in Storesletten (2000), we assume that the income tax rate $\tau$ adjusts to balance the government budget. Other studies show that immigration can affect the generosity of public transfers (Facchini and Mayda, 2009). Alternative fiscal rules are used in the robustness analysis in Appendix B.

\subsection{Monopolistic competitive equilibrium}

Definition 1 For a set of common parameters $\left\{\epsilon, \eta, \sigma_{1}, \sigma_{2}\right\}$, a set of destination-specific parameters $\left\{u_{s}^{0}, \theta_{1}, \theta_{2}, A, \psi, \delta, T_{a, s}^{n}, T_{a, s}^{f} / T_{a, s}^{n}, v\right\}$, and a set of origin-destination specific parameters $\left\{\phi_{a, s}^{o}, N_{a, s}^{o}\right\}$, the monopolistically competitive equilibrium is a set of endogenous variables $\left\{w_{s}^{o}, c_{a, s}^{o}, \gamma_{a, s}^{o}, \ell^{n}, h^{n}, \ell^{f}, h^{f}, y, p, P, B, \tau\right\}$ that satisfies the following conditions:

(i) individuals maximize their utility (1) subject to (2) and (3),

(ii) optimal employment (10) and zero-profit condition (11) holds,

(iii) labor markets clear (i.e., $H^{o}=B h^{o}(i)$ and $L^{o}=B \ell^{o}(i)$ for all $o$ ),

(iv) the government budget (12) is balanced. 


\subsection{Parameterization}

Our model is parameterized to match the economic and socio-demographic characteristics of 20 OECD member states (EU15 countries, the US, Australia, Canada, Japan and Switzerland) in the year 2010. This implies matching the population structure (by age, by education, by origin), income per capita and income disparities between groups of workers, labor markets outcomes, and fiscal data. This section describes the data sources used for parameterizing the model, and discusses the calibration strategy. Table 1 summarizes the calibration outcomes.

Population data $\left(N_{a, s}^{o}\right)$ - In line with Section 2, we use the Database on Immigrants in OECD countries (DIOC) described in Arslan et al. (2015). For each OECD member state, the database covers the census round 2010 and documents the structure of the population by country of origin, by age, by education level, by duration of stay, and by labor market status. We first classify individuals by country of origin (220 countries). Immigrants reporting ex-USSR, exYugoslavia or ex-Czechoslovakia as their origin country are assumed to originate from Russia, Serbia and the Czech Republic, respectively. Immigrants who did not report their origin country are distributed proportionately to observations. Then, we define the college-educated group as individuals who have at least one year of college education or a bachelor degree (ISCED code 5). Those with no education and with pre-primary, primary or secondary education completed are defined as the less educated. We classify individuals who did not report their education level as low-skilled. As for the age structure, we defined individuals aged 25 to 64 as the working aged group; those aged 65 and over form the retiree population. Individuals who did not report their age are assumed to belong to the working age group.

Labor force data $\left(\gamma_{a, s}^{o}, u_{s}^{o}\right)$ - An important feature of the DIOC database is that it includes data on the labor market status. For each origin country and each skill group, we identify the proportions of inactive, active-employed, and active-unemployed individuals aged 25 to 64 . We can thus identify the number of employed, unemployed and inactive individuals for each skill group and for each country of origin.

Income data $\left(Y, w_{s}^{o}\right)$ - In the model, labor is the only factor of production. Hence, the national income is equal to the national gross domestic product (GDP). Aggregate income data are taken from OECD. Stat database; we use the level of GDP in PPP value. By definition, total income is the sum of wages earned by native and immigrant workers. Data on the wage ratio between college-educated and less educated workers are taken from the Education at Glance 2012 report of the OECD; we use them as a proxy for $\bar{w}_{h} / \bar{w}_{l}$. Data on the wage ratio between native and immigrant workers are obtained from Büchel and Frick (2005) and from Docquier et al. (2014); we use them as a proxy for $w_{s}^{n} / w_{s}^{f}$. Using these wage ratios, employment levels and GDP data, we can proxy the wage rate and labor income of each group.

Fiscal data $\left(v, \tau, T_{a, s}^{n}\right)$ - Comparable aggregate data on public finances are obtained from 
the Annual National Accounts harmonized by the OECD. This database reports aggregate public revenues and public expenditures by broad category, as percentage of GDP. We use to identify the consumption tax rate $(v)$ as well as the ratio of public expenditure to GDP, which is equal to $v+\tau$ in our model. We also identify the amount of public consumption and treat it as a homogeneous transfer to all residents (as a part of $T_{a, s}^{o}$ ). Redistributive transfers are also included in $T_{a, s}^{o}$. In line with Aubry et al. (2016), we use the Social Expenditure Database (SOCX) of the OECD to decompose social protection expenditures, and the European Union Statistics on Income and Living Conditions (EU-SILC, provided by Eurostat) to disaggregate education and social protection transfers received by the natives; we identify transfers to natives by education level and by age group. We add these transfers to public consumption per capita and use it as a proxy for $T_{a, s}^{n}$. Finally, we also collect data on the share of unemployment benefits in GDP.

Calibration of common parameters $\left(\epsilon, \sigma_{1}, \sigma_{2}, \eta\right)$ - The model includes four common parameters for which a consensus range of values can be found in the existing literature; benchmark values are reported in the top panel of Table 1. The elasticity of substitution between varieties of goods is estimated in the range of 3 to 8.4 by Feenstra (1994). We assume $\epsilon=7$ as a benchmark value, which means that the model predicts conservative market size effects. As far as elasticities of substitution between groups of worker are concerned $\left(\sigma_{1}\right.$ and $\left.\sigma_{2}\right)$, we follow Ottaviano and Peri (2012) and use $\sigma_{1}=2$ and $\sigma_{2}=20$. Finally, we use $\eta=10$, which implies an elasticity of labor supply to income of 0.1 , as in Evers and De Mooij (2008). We consider alternative levels in the robustness analysis (see Section B in the Appendix).

Country-specific parameters - The model also includes other parameters that vary across countries to match observed economic and socio-demographic characteristics. These parameters capture the cross-country disparities in productivity, in fiscal policies and in labor market institutions. We use all the degrees of freedom of the data to identify these parameters, distinguishing between 10 sets of country-specific parameters and calibrating them to match 10 sets of moments (as summarized in the bottom panel of Table 11). Consequently, our model is exactly identified. Preferences differ across types of individual. The parameter governing the disutility of labor, $\phi_{a, s}^{o}$, is allowed to vary by dyad of country and by skill group. Using (4), it is calibrated to match the observed participation rate, $1-\gamma_{a, s}^{o}$. We obtain a matrix of $220 \times 20$ parameters. The average level is $67 \%$ greater than the disutility parameter of American nonmigrants. Exogenous unemployment rates are directly available from the DIOC data (with a mean of $9.5 \%$ ).

Technological parameters are also allowed to vary across countries. The firms' preferences for workers are calibrated to match the wage ratios between workers. Hence, $\theta_{1}$ is set to match data on $\bar{w}_{h} / \bar{w}_{l}$, while $\theta_{2}$ matches data on $w_{s}^{n} / w_{s}^{f}$. The mean levels of $\theta_{1}$ and $\theta_{2}$ exceed 0.5 . This determines the aggregate quantity of labor in efficiency unit. The TFP level, $A$, is then chosen 
to match the observed level of GDP in PPP value. The mean level of $A$ is $10.5 \%$ smaller than the US level. As for the fixed cost of entry, $\psi$, we equalize it with the number of days required to set up a business, available from the OECD.Stat database and normalized by the US level. The scale of this variable has no impact on our results. The mean level is $43.5 \%$ greater than the US level.

As far as fiscal parameters are concerned, we calibrate the replacement rate $\delta$ to match the observed share of unemployment benefits in GDP. Regarding the other public transfers, the SOCX and SILC data allow us to identify the transfer profile by age and by education level for natives and immigrants. However, the data for immigrants are less precise due to small sample problems. We jointly rescale the transfers to natives $T_{a, s}^{n}$ and calibrate the immigrantto-native ratio of public transfers, $T_{a, s}^{f} / T_{a, s}^{n}$, to match two moments: the observed share of public expenditures in GDP, and the estimated fiscal contribution of immigrants as percentage of GDP. We thus assume that the age and skill profiles of immigrants and natives are different but proportional. On average, $T_{a, s}^{n}$ amounts to $32.1 \%$ of income per capita, and immigrants receive $6.6 \%$ more than natives sharing similar characteristics. As immigrants earn less than the natives and pay less tax, their fiscal contritution is smaller within each age and education cell. However, recent immigrants are younger than natives and contribute positively to public finances. Contrary to Battisti et al. (2017), accounting for the age structure of the immigrant population helps us capturing the fiscal impact of the recent immigration waves. Cross-country estimations of the fiscal impact of the total stock of immigrants are taken from OECD (2013), Tab 3.7. The consumption tax rates is extracted from the OECD Annual National Accounts database. Hence, by definition, the equilibrium income tax rate $\tau$ can be computed from (12) and matches the share of public expenditures in GDP.

\section{Results}

Focusing on 20 selected OECD countries, our goal is to quantify the impact of three recent immigration waves on the welfare of the native population (proxied by the net-of-tax, real income level), and to characterize the role of the changing structure of immigration flows. In the real world, migration decisions are endogenous and depend, among other factors, on the real income at destination and on the size of migration costs. To proxy the "causal" impact of immigration on the welfare of natives, we proceed as in laboratory experiments and simulate the welfare responses to "out-of-equilibrium" migration counterfactuals. Our strategy follows di Giovanni et al. (2015) or Aubry et al. (2016). Firstly, we start from the calibrated model, which takes the observed/equilibrium size and structure of the immigrant population in 2010 as given. Secondly, we identify the size and structure of three cohorts of immigrants: those who arrived between 2001 and 2010, those who arrived between 1991 and 2000 and who were still living 
Table 1: Common and country-specific parameters

\begin{tabular}{|c|c|c|c|c|}
\hline Parameters & Description & Mean & s.d. & Source / Moment matched \\
\hline \multicolumn{5}{|c|}{ Parameters without country variation } \\
\hline$\epsilon$ & Elast. subst. btw goods & 7.0 & n.a. & Feenstra (1994) \\
\hline$\sigma_{1}$ & Elast. subst. btw skills & 2.0 & n.a. & Ottaviano and Peri (2012) \\
\hline$\sigma_{2}$ & Elast. subst. immig/natives & 20 & n.a. & Ottaviano and Peri (2012) \\
\hline $1 / \eta$ & Elast of labor supply & 0.1 & n.a. & Evers et al. (2008) \\
\hline \multicolumn{5}{|c|}{ Parameters varying across countries } \\
\hline$\phi_{a, s}^{o}$ & Disutility of labor (relative to US) & 1.675 & 1.487 & Matches $\gamma_{a, s}^{o}$ \\
\hline$u_{s}^{o}$ & Unemployment rates & 0.095 & 0.072 & Matches DIOC data \\
\hline$\theta_{1}^{\circ}$ & Firms' preference HS & 0.557 & 0.050 & Matches $\bar{w}_{h} / \bar{w}_{l}$ \\
\hline$\theta_{2}$ & Firms' preference native & 0.527 & 0.040 & Matches $w_{s}^{n} / w_{s}^{f}$ \\
\hline$A$ & TFP (relative to US) & 0.894 & 0.294 & Matches total GDP \\
\hline$\psi$ & Cost of entry (relative to US) & 1.435 & 0.952 & $\mathrm{Nb}$. days to create a firm \\
\hline$\delta$ & Replacement rate & 0.600 & 0.300 & Matches unemp/GDP \\
\hline$T_{a, s}^{n}$ & Public transfers (\% of GDPpc) & 0.321 & 0.089 & Matches gov. exp/GDP \\
\hline$T_{a, s}^{f, s} / T_{a, s}^{n}$ & Ratio of public transfers & 1.066 & 0.467 & Matches fiscal cont. immig \\
\hline$v$ & Consumption tax rate & 0.173 & 0.042 & Matches OECD data \\
\hline
\end{tabular}

in the destination country in 2010, and recent immigrants who arrived between 2011 and 2015 (forming the post-crisis wave). Thirdly, we use the model to simulate the welfare responses to three counterfactual immigration scenarios. In the first one, we eliminate the 2001-2010 immigration cohort from the stock of immigrants in 2010 those who arrived between 2001 and 2010 (as if migration costs had been prohibitively high over that period); in the second one, we eliminate the 1991-2000 cohort; in the third one, we add the 2011-2015 cohort.7 We compute the real income responses to immigration by reference to the 2010 levels, assuming that all country-specific characteristics (productivity, fiscal policy, labor market institutions) as well as the size and structure of the native population are unaffected. 8

Due to return migration, mortality and changing incentives to migrate, the 1991-2000 counterfactual differs in size from the 2001-2010 one. Similarly, the 2011-2015 shock is smaller as it only covers a period of 5 years following the last economic crisis. These shocks induce varying effects on the proportion of immigrants in the total population. Defining the share of foreigners in the host-country population as $m \equiv \sum_{a, s} \sum_{o=f_{1}}^{f_{F}} N_{a, s}^{o} /\left(\sum_{a, s} \sum_{o=f_{1}}^{f_{F}} N_{a, s}^{o}+N_{a, s}^{n}\right)$, we can assess the contribution of each immigrant wave (i.e., 1991-2000, 2001-2010 and 2011-2015) to the total share of foreigner. We denote this contribution by $\Delta m$. To identify the effect of the changing structure of immigration, we express the macroeconomic and welfare responses in

\footnotetext{
${ }^{7}$ In our simulations, we assume that eliminating one immigration wave does not affect the size and structure of the other waves.

${ }^{8}$ Note that this implies that we neglect immigration effects on the educational and occupational structure of natives. In particular, recent evidence suggests that immigration creates geographic as well as (more importantly from our viewpoint) occupational displacement, mostly upward (see e.g., Foged and Peri (2016), for Denmark, or Ortega and Verdugo (2016), for France). By neglecting these effects, we somewhat underestimate the benefits from immigration.
} 
relative terms by dividing all effects by $\Delta m$; we thus report semi-elasticities of macroeconomic variables and welfare to immigration. For each type of native individual in the year 2010, the semi-elasticity of real income to immigration can be expressed as:

$$
\frac{\Delta C_{a, s}^{n} / C_{a, s}^{n}}{\Delta m}=\frac{\left(C_{a, s}^{n}\right)_{\text {With Mig }}-\left(C_{a, s}^{n}\right)_{\text {Without Mig }}}{\Delta m\left(C_{a, s}^{n}\right)_{\text {Without Mig }}} .
$$

The relative change in real income is expressed as percentage deviation from the no-migration counterfactual (i.e., after eliminating the 1991-2000 or 2001-2010 pre-crisis waves in the first two experiments, or before adding the 2011-2015 post-crisis wave in the third experiment). Hence, a positive deviation implies a welfare gain due to the immigration wave, while a negative deviation implies a welfare loss. The same expression is used when discussing the effect on any extensive macroeconomic variable (in USD). When describing the effect on intensive variables (i.e., a variable which does depend on the volume of the system, such as the tax rate, the (un)employment rate, the proportion of college graduates, the support ratio, etc.), we simply divide the numerator of the expression above by $\Delta m$.

The model accounts for four interdependent mechanisms of transmission. Two of them work through the labor market. Firstly, immigration affects the size and structure of the labor force. The greater the employment rate of immigrants, the larger the labor supply shock. The latter induces responses in nominal wages. The skill structure of immigration determines who wins and who loses among natives. Other things being equal, immigration also induces a wage surplus for natives (i.e., the wage gains for the winners exceed the wage losses for the losers); the size of this wage surplus is small in this type of model (Borjas, 1995). Secondly, wage responses affect the participation rates of natives and former immigrants. Thirdly, immigration affects the amounts of public revenues and expenditures. If it induces a fiscal gain, immigration reduces the equilibrium tax rate; otherwise, the tax rate increases. In our experiments, immigration usually generates a fiscal gain. Given the transfer profiles by age and by skill group, the fiscal contribution of immigrants increases with their education level and with their employment rate. Fourthly, immigration increases the total demand for goods and services, which supports entrepreneurship and the number of varieties available to consumers. Hence, the ideal price index decreases. General equilibrium interdependencies result from the fact that responses in nominal wages, tax rates and prices affect labor-market participation rates and vice versa. The real income of working-age natives is affected by wages, taxes, prices, and labor supply decisions. Native retirees, on the other hand, are assumed to receive no labor income, to pay no taxes, and to be affected only through the market size channel (i.e., by the price response to immigration).

In this section, we first describe the three immigration waves in Section (4.1). We then 
discuss the macroeconomic effects of immigration in Section (4.2). Section (4.3) describes the welfare and inequality implications for the native population.

\subsection{Immigration cohorts}

We describe the effects of the counterfactuals on socio-demographic variables, i.e. on the population size, on the proportion of college graduates in the working age population, $h \equiv$ $\sum_{o} N_{y, h}^{o} / \sum_{o, s} N_{y, s}^{o}$, and on the support ratio defined as the ratio of working age residents to population: $s \equiv \sum_{o, s} N_{y, s}^{o} / \sum_{o, a, s} N_{a, s}^{o}$.

The first counterfactual consists of eliminating immigrants who arrived between 2001 and 2010. Data on immigrants by duration of stay, by origin country and by education level are available from the DIOC database. The same database can be used to characterize the second counterfactual, which consists in eliminating immigrants who arrived between 1991 and 2000. These cohorts are not perfectly comparable: immigrants arrived between 1991 and 2000 are older and had more opportunities to return to their home country. Hence, the remaining members of this cohort in the year 2010 can be more or less educated than those of the next cohort for other reasons than the changing origin mix. This must be kept in mind when comparing the two pre-crisis waves.

As for the third counterfactual, data on the 2011-15 inflow by education level are not available. We use the United Nations data and compute the growth rates of dyadic immigrant stocks between 2010 and 2015. We apply these growth rates to the stock of working age immigrants in 2010, and assume that the additional immigrants have the same education level as migrants from the same origin country arrived between 2001 and 2010. Hence, in the third experiment, the effect of immigration on human capital is totally governed by the changing origin mix of the migrant inflows after the crisis. In the Appendix, we show that this method is highly relevant to predict the skill structure of immigration of past immigrant waves. This is because the dyadic education structure is very stable across cohorts. This does not fully guarantee that it is identically relevant to predict the structure of the post-crisis wave, but it mitigates concerns about the unavailability of education data for the latter cohort. We also assume that all adult immigrants from these three waves belong to the working age population.

Figure 3 characterizes the socio-demographic effects of these three immigration waves. The left panel (Fig 3, a, 3,c and 3,e) compares the effect of the 1991-2000 wave on the horizontal axis with that of the 2001-2010 wave on the vertical axis. The right panel (Fig 3.b, 3. d and 3,f) compares the effect of the 2001-2010 wave on the horizontal axis with that of the 2011-2015 wave on the vertical axis. The 45-degree line allows visualizing which wave dominates.

Figures 3 a and 3 b depict the size of the shocks $(\Delta m)$. Comparing 1991-2000 with 20012010, the average shock sizes equal 3.7 and 5.1 percentage points, respectively. The 2001- 
2010 wave is larger in 11 countries, including France, Belgium, the United Kingdom, Australia and Sweden. Changes are drastic in Ireland and Luxembourg. On the contrary, the 1991-2000 waves dominates in 8 countries, including Switzerland, Germany, Austria and, to a lesser extent, Canada and the United States. Comparing 2001-2010 with 2011-2015, the average shock sizes equal 5.1 and 1.6 percentage points, respectively (the latter corresponds to a 3.2 p.p. shock over a decade). Overall, Figure 3,b shows that the pre- and post-crisis trends are very similar; this means that most observations are close to the 22.5-degree line (i.e., the 5-year shock of 20112015 is slightly smaller than half the 10-year shock of 2001-2010). Exceptions are Belgium and Luxembourg, where the post-crisis migration inflows are larger, and Ireland, where they are smaller. Remember that in equation (13), we neutralize the size of the shock $(\Delta m)$ when interpreting its welfare implications, in order to highlight the role of the changing structure of immigration.

Figures 3.c and 3. d depict the effect on the support ratio $(\Delta s / \Delta m)$. Changes in the age structure govern the fiscal responses to migration. By definition, the semi-elasticity is equal to the ratio of retirees to population and is independent of the size and structure of immigration. Hence, the effect of immigration is greater in countries with older populations (such as Germany, Luxembourg, Austria, Italy or Sweden), and smaller in countries with younger populations (such as Canada, United States, Australia, Ireland). Hence, immigration increases the support ratio everywhere, and particularly in countries where the median age of the native population is low. This effect does not vary across immigrant cohorts.

As far as the education level is concerned, it varies with the origin mix and with the degree of self-selection of immigrants. The latter is affected by (unmodelled) dyadic and destination characteristics such as the immigration policy, linguistic proximity, colonial links, geographic distances, the industry structure, etc. Figures 3 e and 3 f depict the effect of immigration on the proportion of college graduates $(\Delta h / \Delta m)$. Changes in human capital govern the productivity and inequality responses to migration. The two figures show a remarkable persistence across immigration waves. Countries where immigration increases human capital include Australia, Canada and the United Kingdom (i.e., countries conducting quality-selective immigration policies) as well as Luxembourg. On the contrary, immigration reduces human capital in Scandinavia, Belgium or Greece. Between 2001 and 2010, immigration increases human capital in Switzerland and decreases it in Portugal. Figure 3.f shows that most observations are located below the $45^{\circ}$ line, implying that, with very few exceptions, the post-crisis immigration wave is relatively less educated than the previous one. This potentially affects their market size and fiscal impacts of immigration. 
3.a. Proportion of Foreigners $(\Delta \mathrm{m})$

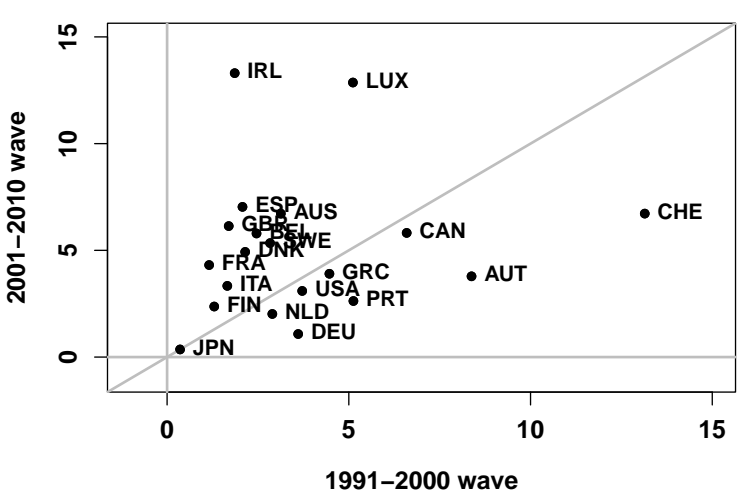

3.c. Support ratio $(\Delta \mathbf{s} / \Delta \mathbf{m})$

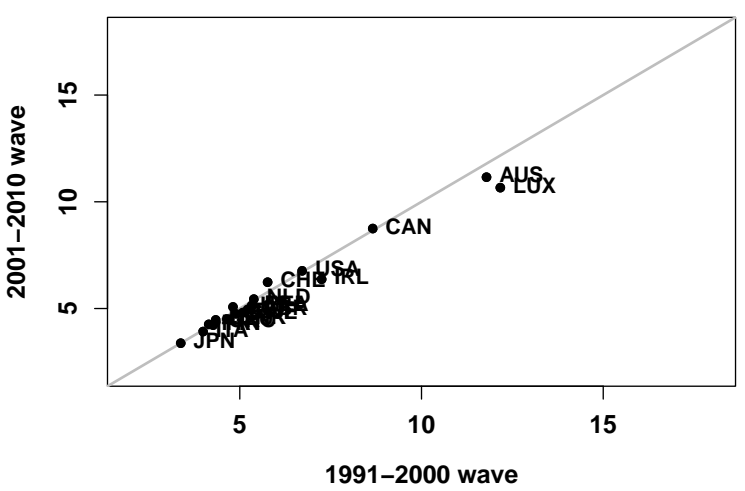

3.e. Proportion of college graduates $(\Delta h / \Delta m)$

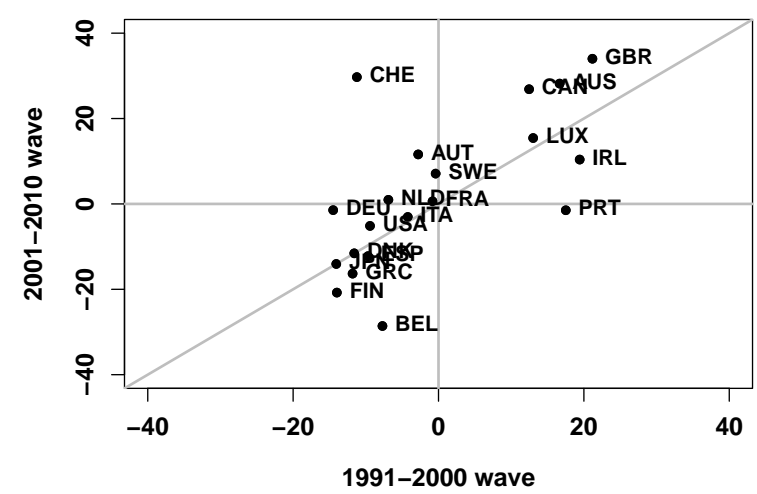

3.b. Proportion of Foreigners $(\Delta \mathrm{m})$

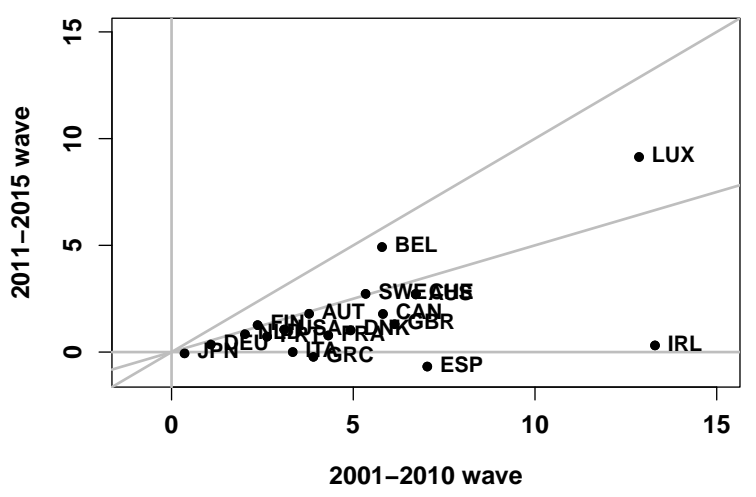

3.d. Support ratio $(\Delta \mathbf{s} / \Delta \mathbf{m})$

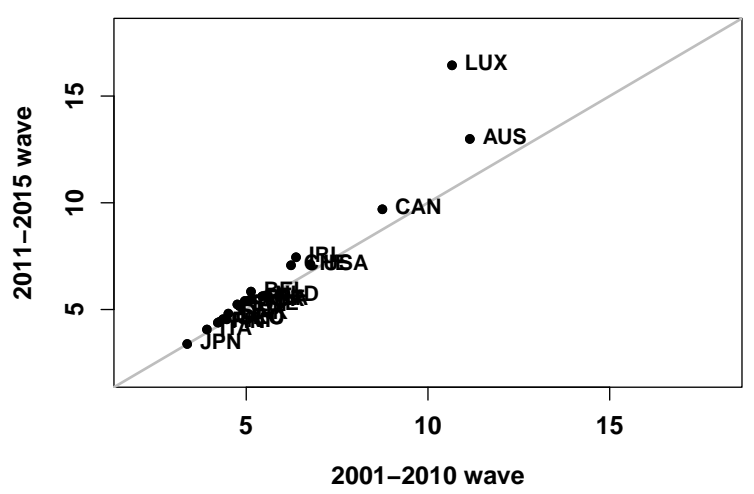

3.f. Proportion of college graduates $(\Delta \mathrm{h} / \Delta \mathrm{m})$

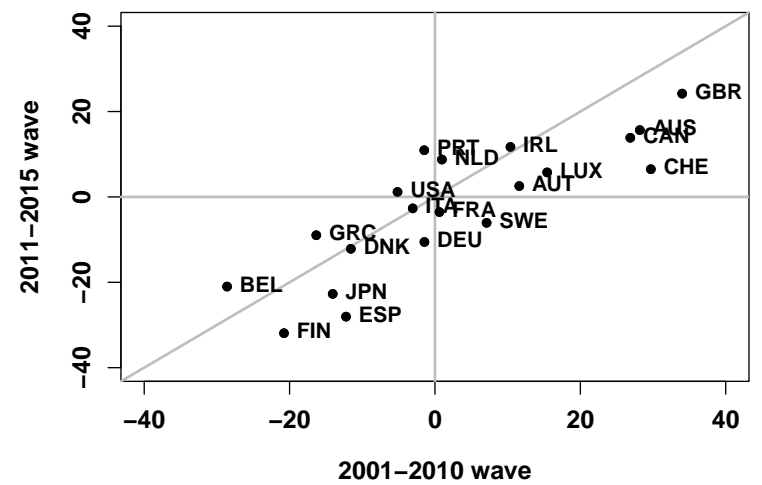

Figure 3: Socio-demographic effects of three immigration waves ( $\Delta m$ and semi-elasticity to $\Delta m)$

Notes. Figure 3 shows the results for 20 selected countries: the 15 members states of the European Union (EU15), the US, Canada, Australia, Switzerland and Japan. The left panel compares the effects of the 1991-2000 and 20012010 immigration waves. The right panel compares the effects of the 2011-2015 and 2001-2010 immigration waves. The diagonal is the 45 degree line. 


\subsection{Macroeconomic effects}

Figure 4 characterizes the macroeconomic effects of the three immigration waves. We focus on the average employment rate, the income tax rate and the average price index. As before, the left panel (Figures 4.a, 4.c and 4.e) compares the effect of the 1991-2000 wave with that of the 2001-2010 wave. The right panel (Figures 4,b, 4, d and 4.f) compares the effect of the 2001-2010 wave with that of the 2011-2015 wave?

Figures $4 \mathrm{a}$ and $4 \mathrm{~b}$ depict the aggregate employment effects of immigration. These effects mostly depend on the average disutility of labor and induced participation rates of immigrants and, to a lesser extent, on the endogenous labor-market participation responses of the natives. There are a few countries where immigration increases the average employment rates (e.g., the poorer countries of Europe). On the contrary, immigration reduces employment rates in countries where immigrants exhibit higher disutility for labor (such as Scandinavian countries and Belgium). The comparison between cohorts reveals very small differences. In particular, despite its lower level of education, the 2011-2015 wave induces very similar effects compared to the pre-crisis waves. This is because the correlation between the employment and human capital levels of immigrants is limited in the data (around 0.5). Hence, employment responses are very persistent across immigration waves: the degradation of immigrant's human capital after the crisis has small effects on the employment response to immigration, as evidenced from Figure $4 \mathrm{~b}$.

Figures 4.c and 4.d illustrate the market size effect of immigration. Using a conservative elasticity of substitution between goods $(\epsilon=7)$, we obtain non negligible effects on the average price index. On average, increasing the immigration share by one percentage point reduces the average price level by $0.24 \%$ in 1991-2000 and in 2001-2010. A similar magnitude of the market size effect can be observed for the 2011-2015 period. The price elasticity to migration depends on changes in human capital and employment rates. Again, these figures show a strong persistence over immigration waves. Countries where market size effects are large are Australia, Canada, Luxembourg, Ireland. The effect is smaller in Scandinavian countries and Belgium. Remember the market size mechanism is the only channel through which native retirees are economically affected by immigration (due to the fixed-benefit fiscal rule). Figure $4 . \mathrm{c}$ and $4 \mathrm{~d}$ thus depict the impact of immigration on the real income of retirees; this effect is positive in all countries and across all waves.

The fiscal impact of immigration is described in Figures 4 .e and 4 f. Remember that for each country, our model is calibrated to match the estimated fiscal contribution of the total stock of immigrants. The latter contribution is the sum of the fiscal costs induced by old immigrants and the fiscal gains induced by younger immigrants. In our experiments, recent immigration flows

\footnotetext{
${ }^{9}$ For detailed country-specific results, please consult Table $\mathrm{C} 2$
} 
4.a. Employment rates $(\Delta \mathrm{e} / \Delta \mathrm{m})$

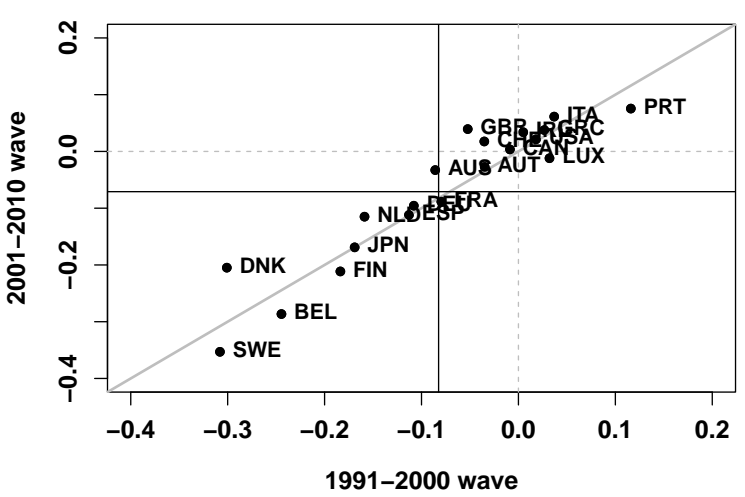

4.c. Price index $(\Delta \mathrm{P} / \mathrm{P} / \Delta \mathrm{m})$

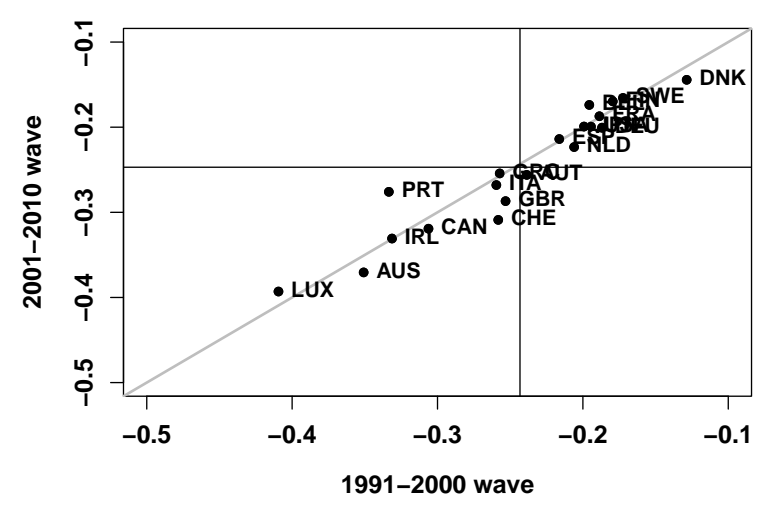

4.e. Income tax rate $(\Delta \tau / \Delta \mathrm{m})$

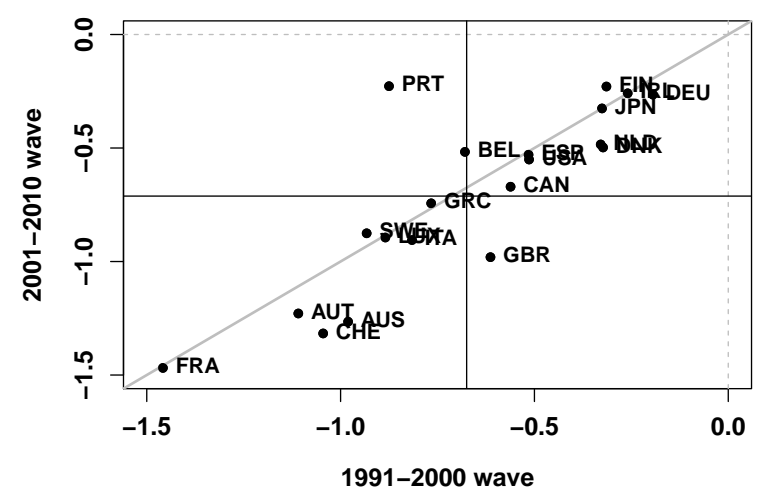

4.b. Employment rates $(\Delta \mathrm{e} / \Delta \mathrm{m})$

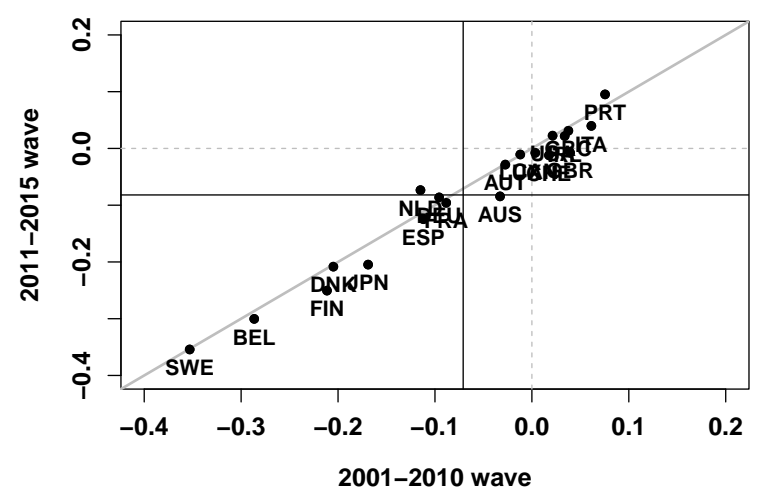

4.d. Price index $(\Delta P / P / \Delta m)$

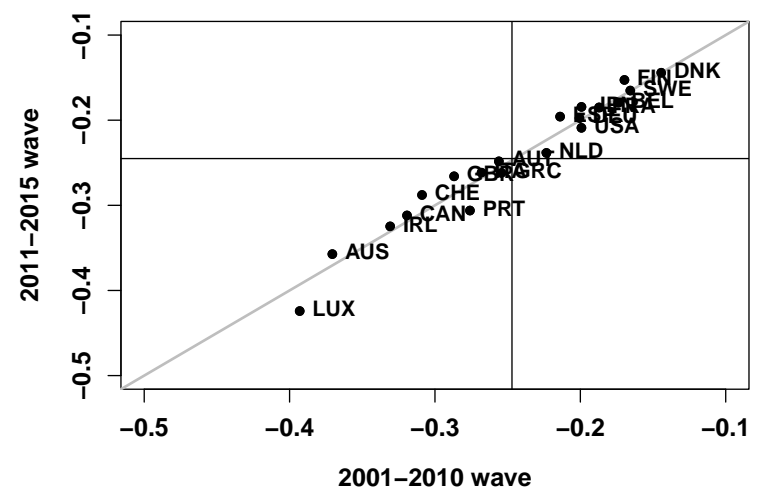

4.f. Income tax rate $(\Delta \tau / \Delta \mathrm{m})$

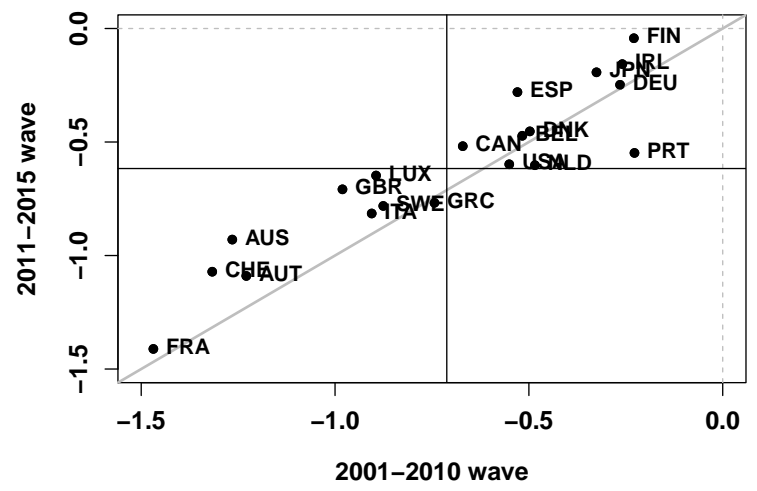

Figure 4: Macroeconomic effects of three immigration waves (Semi-elasticity to $\Delta m$ )

Notes. Figure 4 shows the results for 20 selected countries: the 15 members states of the European Union (EU15), the US, Canada, Australia, Switzerland and Japan. The left panel compares the effects of the 1991-2000 and 20012010 immigration waves. The right panel compares the effects of the 2011-2015 and 2001-2010 immigration waves. The semi-elasticity is defined as the ratio of the percentage of deviation in $\mathrm{X}$ to the change in the immigration rate. The diagonal is the 45 degree line. Black solid lines represent unweighted averages effects across countries for each immigration wave. 
make the population younger. Although immigrants receive higher transfers than natives sharing similar characteristics, young immigrants generate a positive contribution to public finances. On average, increasing the immigration share by one percentage point reduces the income tax rate by 0.67 percentage point in 1991-2000, by 0.71 percentage point in 2001-2010, and by 0.62 percentage point in 2011-2015. The fiscal impact is strongly persistent across waves; its size is governed by fiscal policy and by the age structure of the population. Countries exhibiting large fiscal gains are France, Switzerland and Austria (i.e., countries where population aging has reached an advanced stage or where immigrants receive relatively less transfers). Countries where fiscal gains are consistently smaller are Canada, Germany, the United States (i.e., countries where the population is younger or where immigrants receive relatively more transfers). In the majority of countries, the decrease in the average education level of post-crisis immigrants results in smaller fiscal gains for natives.

\subsection{Welfare and inequality effects}

We now aggregate the transmission channels and compute the welfare implications of immigration for the natives. As stated above, we use the net-of-tax, real income level as a proxy for utility. Figure 5 gives the effect on the average real income of working age natives, and the effect on the real income ratio between young college-educated natives and the less educated. The latter inequality response is essentially governed by the wage effect of immigration: the income ratio increases if immigrants are less educated than working age natives, and decreases otherwise. The wage effect is slightly amplified by changes in labor market participation rates. On the contrary, these labor market responses have limited effects on the average real income of natives because the immigration wage surplus per se is small (Borjas, 1995). Hence, the average income response is mostly governed by the fiscal and market size effects of immigration, which affect all working age natives with the same intensity. The left panel (Figures 5 a and 5.c) compares the effect of the 1991-2000 wave on the horizontal axis with that of the 20012010 wave on the vertical axis. The right panel (Figures 5 b and 5 d) compares the effect of the 2001-2010 wave on the horizontal axis with that of the 2011-2015 wave on the vertical axis.

Figures 5 a and 5b bhow that immigration always increases the real income of working age natives. In addition, cross-country disparities in the average welfare gain are strongly persistent across immigration waves. The largest immigration gains are obtained in Australia, Austria, France, Luxembourg, Switzerland and the United Kingdom. The smallest gains are observed in Scandinavian countries, Germany, Belgium, Spain and the United States. The latter set of countries exhibit smaller fiscal and market size gains from immigration. The 20012010 immigration wave induces very similar effects as the 1991-2000 one, although the gain increases for Swiss and British natives, and decreases for the Portuguese. On the contrary, 
Figure 5,b shows that the post-crisis wave is relatively less beneficial in the vast majority of countries. Consistently with Figure 4 , this can be explained by the changing origin-mix of immigrants, which affects the level of human capital and the fiscal benefits from immigration.
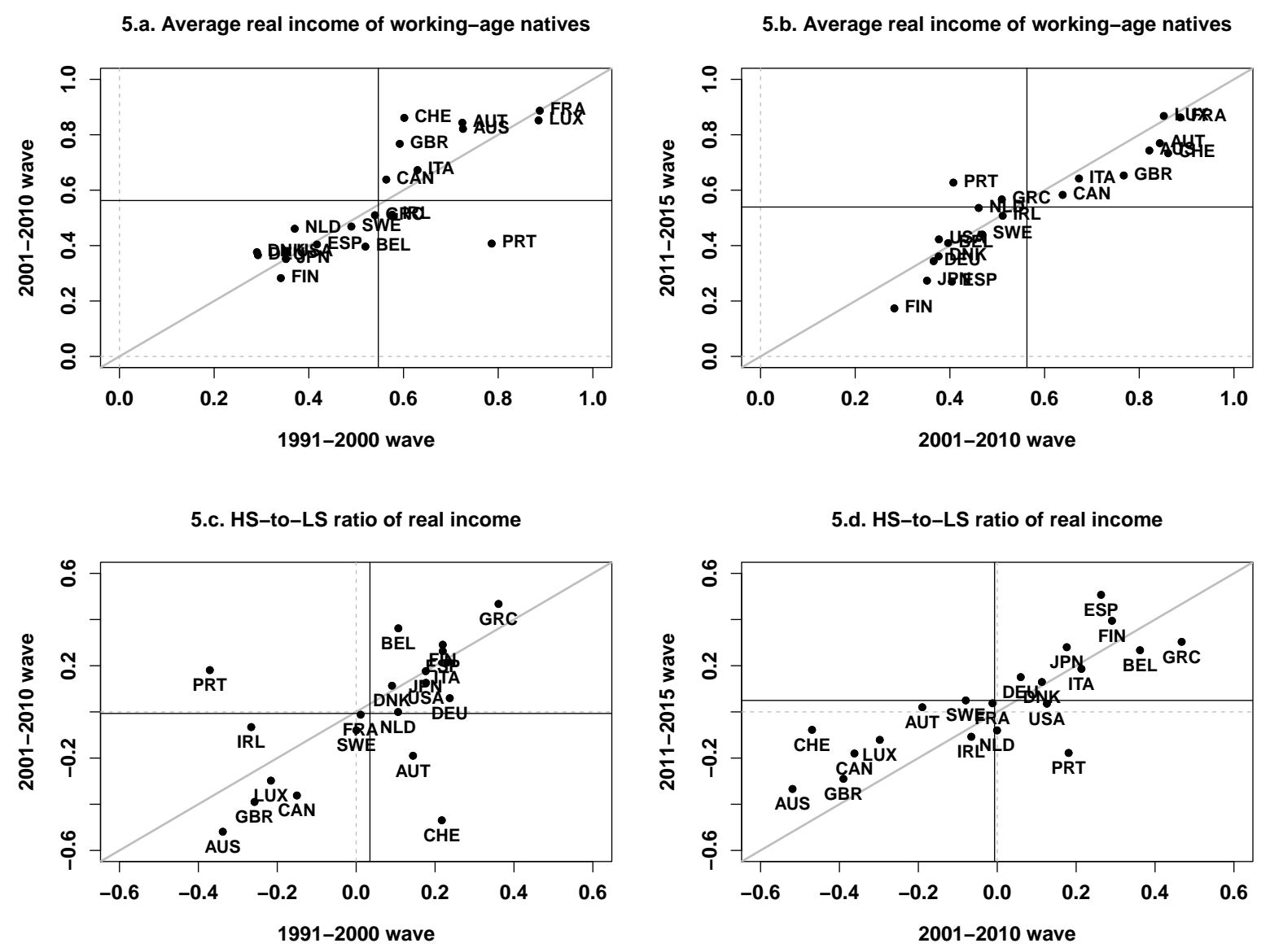

Figure 5: Welfare impact of three immigration waves (Semi-elasticity to $\Delta m$ )

Notes. Figure 5 shows the results for 20 selected countries: the 15 members states of the European Union (EU15), the US, Canada, Australia, Switzerland and Japan. The left panel compares the effects of the 1991-2000 and 20012010 immigration waves. The right panel compares the effects of the 2011-2015 and 2001-2010 immigration waves. The semi-elasticity is defined as the ratio of the percentage of deviation in $\mathrm{X}$ to the change in the immigration rate. The diagonal is the 45 degree line. Black solid lines represent unweighted averages effects across countries for each immigration wave.

Figures $5 \mathrm{c}$ and $5 \mathrm{~d}$ depict the effect on inequality in real income, as defined by the ratio of real income between college-educated and less educated natives aged 25 to 64. Although we identify a high degree of persistence in cross-country disparities, persistence is smaller than for macroeconomic variables and average effects. Large variations across waves are observed in Portugal and Switzerland. Overall, it comes out that all immigration waves increase inequality in the majority of countries. This is particularly the case in Scandinavian countries, Belgium, Spain, Greece. The effect is small in countries such as France, Austria or the United States. 
Immigration decreases inequality in countries where migrants are positively selected such as Luxembourg, Australia, Canada and the United Kingdom. This being said, the impact on the real income of low-skilled natives is almost always positive, as the fiscal and market size effects dominate labor market effects. The only exceptions are Spain, Japan and Greece after the 20112015 wave, where the semi-elasticity of income to migration is negative but virtually nil (the loss is smaller than $0.1 \%$ ). Figure 5 d shows that the post-crisis cohort induces more inegalitarian (or less egalitarian) effects than the pre-crisis cohort in two thirds of the countries. The opposite effect is found in the rest of the sample.

Overall, the key findings of our analysis are that (i) the last three waves of immigration have not deteriorated the real income of the native population, (ii) that the distribution of the gains vary across countries and across skill groups as a function of the structure of immigration, (iii) that these redistributive effects are strongly persistent over time, and (iv) that the post-crisis immigration waves is less beneficial for natives than the previous ones, and more inegalitarian in the majority of countries (keeping in mind that its skill structure is not directly observable, but is estimated). In the Appendix, we show that the results of the benchmark model are highly robust to the choice of parameters, to the inclusion of technological externalities, and to alternative fiscal rules.

\section{Concluding remarks}

Despite large changes in the number and in the origin-mix of immigrants, little is known about the evolution of their welfare impact on the native populations in the OECD member states. This paper compares the welfare implications of two pre-crisis immigration waves (1991-2000 and 2001-2010) to those of the post-crisis wave (2011-2015). Our analysis relies on a general equilibrium model that accounts for the main channels of transmission of immigration shocks - the employment and wage effects, the fiscal effect, and the market size effect - and for the interactions between them. Focusing on 20 selected OECD member states, we find that the three waves induce positive effects on the real income of natives, although the size of these gains varies across countries and across skill groups. For example, we estimate that increasing the immigrant share in the total population by one percentage point raises the average income of natives by $0.5 \%$ in the OECD member states. However, this effect varies between $0.3 \%$ in Finland and $0.9 \%$ in Luxembourg. As far as income inequality is concerned, the same inflow of immigrants increases the ratio of real income between college graduates and the less educated by $0.5 \%$ in Greece, and decreases it by $0.5 \%$ in Australia. These average welfare gain and inequality effects are strongly persistent across immigration waves. In relative terms, the post-crisis wave induces smaller welfare gains compared to the previous ones (on average, $0.02 \%$ for each percentage point of immigration). This is due to the changing origin-mix of 
immigrants, which translates into lower levels of human capital and smaller fiscal gains. This overall result applies to all OECD countries and to all categories of native citizens. However, differences across cohorts explain a tiny fraction of the highly persistent, cross-country heterogeneity in the economic benefits from immigration. This heterogeneity is presumably governed by enduring destination characteristics such as the immigration policy, the wage structure, or the industry structure. This implies that the economic consequences of the changing origin mix of immigrants should not be overestimated.

\section{References}

Abramitzky, R., Boustan, J., and Eriksson, K. (2012). Europe's tired, poor, huddled masses: Self-selection and economic outcomes in the age of mass migration. American Economic Review, 102(5):1832-1856.

Alesina, A., Harnoss, J., and Rapoport, H. (2016). Birthplace diversity and economic prosperity. Journal of Economic Growth, pages 1-32.

Ambrosini, J. and Peri, G. (2012). The determinants and the selection of mexico-us migrants. World Economy, 35(2):111-151.

Anderson, J. E., Larch, M., and Yotov, Y. V. (2016). Trade liberalization, growth, and fdi: A structural estimation framework.

Arslan, C., Dumont, J.-C., Kone, Z., Moullan, Y., Özden, c., Parsons, C., and Xenogiani, T. (2015). A new profile of migrants in the aftermath of the recent economic crisis. OECD Social, Employment and Migration Working Papers, (160).

Aubry, A., Burzyński, M., and Docquier, F. (2016). The welfare impact of global migration in oecd countries. Journal of International Economics, 101:1-21.

Bahar, D. and Rapoport, H. (2017). Migration, knowledge diffusion and the comparative advantage of nations. Economic Journal, forthcoming.

Battisti, M., Felbermayr, G., Peri, G., and Poutvaara, P. (2017). Immigration, search and redistribution: A quantitative assessment of native welfare. Journal of the European Economic Association.

Borjas, G. J. (1993). Immigration policy, national origin, and immigrant skills: A comparison of canada and the united states. In: Small Differences that Matter: Labor Markets and Income Maintenance in Canada and the United States, D. Card and R.B. Freeman (eds.), University of Chicago Press.

Borjas, G. J. (1995). The economic benefits from immigration. Journal of Economic Perspectives, 9(2):3-22. 
Borjas, G. J. and Trejo, S. J. (1993). National origin and immigrant welfare recipiency. Journal of Public Economics, 50(3):325-344.

Büchel, F. and Frick, J. R. (2005). Immigrants economic performance across Europe-does immigration policy matter? Population Research and Policy Review, 24(2):175-212.

Card, D. (2009). Immigration and inequality. American Economic Review, 99(2):1-21.

Chiquiar, D. and Hanson, G. (2005). International migration, self-selection and the distribution of wages: Evidence from mexico and the united states. Journal of Political Economy, 113(2):239-281.

de la Croix, D. and Docquier, F. (2012). Do brain drain and poverty result from coordination failures? Journal of Economic Growth, 17(1):1-26.

di Giovanni, J., Levchenko, A. A., and Ortega, F. (2015). A global view of cross-border migration. Journal of the European Economic Association, 13(1):168-202.

Docquier, F., Ozden, Ç., and Peri, G. (2014). The labour market effects of immigration and emigration in oecd countries. Economic Journal, 124(579):1106-1145.

Docquier, F., Turati, R., Valette, J., and Vasilakis, C. (2016). Multiculturalism and growth: Skill-specific evidence from the post-world war II period. IRES Discussion Papers, (28).

Evers, M. and De Mooij, R Van Vuuren, D. (2008). The wage elasticity of labour supply: a synthesis of empirical estimates. De Economist, 156(1):25-43.

Facchini, G. and Mayda, A. M. (2009). Does the welfare state affect individual attitudes toward immigrants? evidence across countries. The Review of Economics and Statistics, 91(2):295314.

Feenstra, R. C. (1994). New product varieties and the measurement of international prices. American Economic Review, 84(1):157-177.

Felbermayr, G. J., Jung, B., and Toubal, F. (2010). Ethnic networks, information, and international trade: Revisiting the evidence. Annals of Economics and Statistics/Annales dâĂŹEconomie et de Statistique, pages 41-70.

Felbermayr, G. J. and Toubal, F. (2012). Revisiting the trade-migration nexus: Evidence from new oecd data. World Development, 40(5):928-937.

Feyrer, J. (2009). Trade and income-exploiting time series in geography.

Foged, M. and Peri, G. (2016). Immigrants' effect on native workers: New analysis on longitudinal data. American Economic Journal: Applied Economics, 8(2):1-34.

Iranzo, S. and Peri, G. (2009). Migration and trade: Theory with an application to the easternwestern european integration. Journal of International Economics, 79(1):1-19. 
Javorcik, B. S., Özden, Ç., Spatareanu, M., and Neagu, C. (2011). Migrant networks and foreign direct investment. Journal of Development Economics, 94(2):231-241.

Kaestner, R. and Malamud, O. (2014). Self-selection and international migration: New evidence from mexico. Review of Economics and Statistics, 96(1):78-91.

Kerr, W. R. (2017). Heterogeneous technology diffusion and ricardian trade patterns. World Bank Economic Review.

Krugman, P. (1980). Scale economies, product differentiation, and the pattern of trade. American Economic Review, pages 950-959.

Kugler, M. and Rapoport, H. (2007). International labor and capital flows: Complements or substitutes? Economics Letters, 94(2):155-162.

McKenzie, D. and Rapoport, H. (2010). Self-selection patterns in mexico-us migration: the role of migration networks. Review of Economics and Statistics, 92(4):811-821.

Moraga, J. F.-H. (2011). New evidence on emigrant selection. Review of Economics and Statistics, 93(1):72-96.

Moretti, E. (2004a). Estimating the social return to higher education: evidence from longitudinal and repeated cross-sectional data. Journal of Econometrics, 121(1):175-212.

Moretti, E. (2004b). Workers' education, spillovers, and productivity: evidence from plant-level production functions. American Economic Review, 94(3):656-690.

OECD (2013). The fiscal impact of immigration in oecd countries. International Migration Outlook.

Ortega, F. and Peri, G. (2014). Openness and income: The roles of trade and migration. Journal of International Economics, 92(2):231-251.

Ortega, J. and Verdugo, G. (2016). Moving up or down? immigration and the selection of natives across occupations and locations. Working Paper, UniversitÃl' Paris 1 PanthÃl'onSorbonne.

Ottaviano, G. I. and Peri, G. (2012). Rethinking the effect of immigration on wages. Journal of the European Economic Association, 10(1):152-197.

Özden, Ç., Parsons, C. R., Schiff, M., and Walmsley, T. L. (2011). Where on earth is everybody? the evolution of global bilateral migration 1960-2000. World Bank Economic Review, 25(1):12-56.

Parsons, C. R. and Vézina, P.-L. (2017). Migrant networks and trade: The vietnamese boat people as a natural experiment. Economic Journal, forthcoming.

Steingress, W. (2015). The causal impact of migration on us trade: Evidence from a natural experiment. IZA Working Paper, (9058). 
Storesletten, K. (2000). Sustaining fiscal policy through immigration. Journal of Political Economy, 108(2):300-323.

United Nations (2014). United nations global migration database (ungmd). United Nations Department of Economic and Social Affairs Population Division. 


\section{Supplementary appendix}

\section{A Comparability between cohorts}

Two different methods are used to identify the size and structure of the pre-crisis (2001-10) and post-crisis (2011-15) immigrant cohorts. For the pre-crisis waves, we directly identify the number and characteristics of immigrants arrived between 2001 and 2010 (or between 1991 and 2000) using DIOC data by duration of stay. For the post-crisis wave, we proxy their number using the relative variation in dyadic immigrant stocks between 2010 and 2015 from the United Nations database. We then proxy their education level using the dyadic education structure of the previous wave. This method is relevant if the dyadic education structure of immigration is stable over time. To validate our hypothesis, in Figure A1 a we use the same method and retrospectively predict the education structure of the 1991-2000 wave. We can then compare our "backcasts" with the observed structure; the correlation between predicted and observed structure of 1991-2000 immigrant cohort equals 0.97. We are thus confident that our imputation method does not drive the results.

Another difference is that the welfare effect of the pre-crisis wave is computed using a 10-year inflow of immigrants, while the effect of the post-crisis wave is computed using a 5year inflow. As the model is nonlinear, one may fear that the size of the shock matters and that our semi-elasticities are not comparable. To check this, we simulated the effect of the post-crisis wave on a 10-year basis, assuming that the size and structure of the 2016-2021 inflow are identical to those of the 2011-15 inflow. The outcomes are presented in Figure A1.b. The correlation between the semi-elasticities computed using 5-year and 10-year shocks equal 0.998. We are thus confident that our comparative results are not driven by differences in the size of immigration.
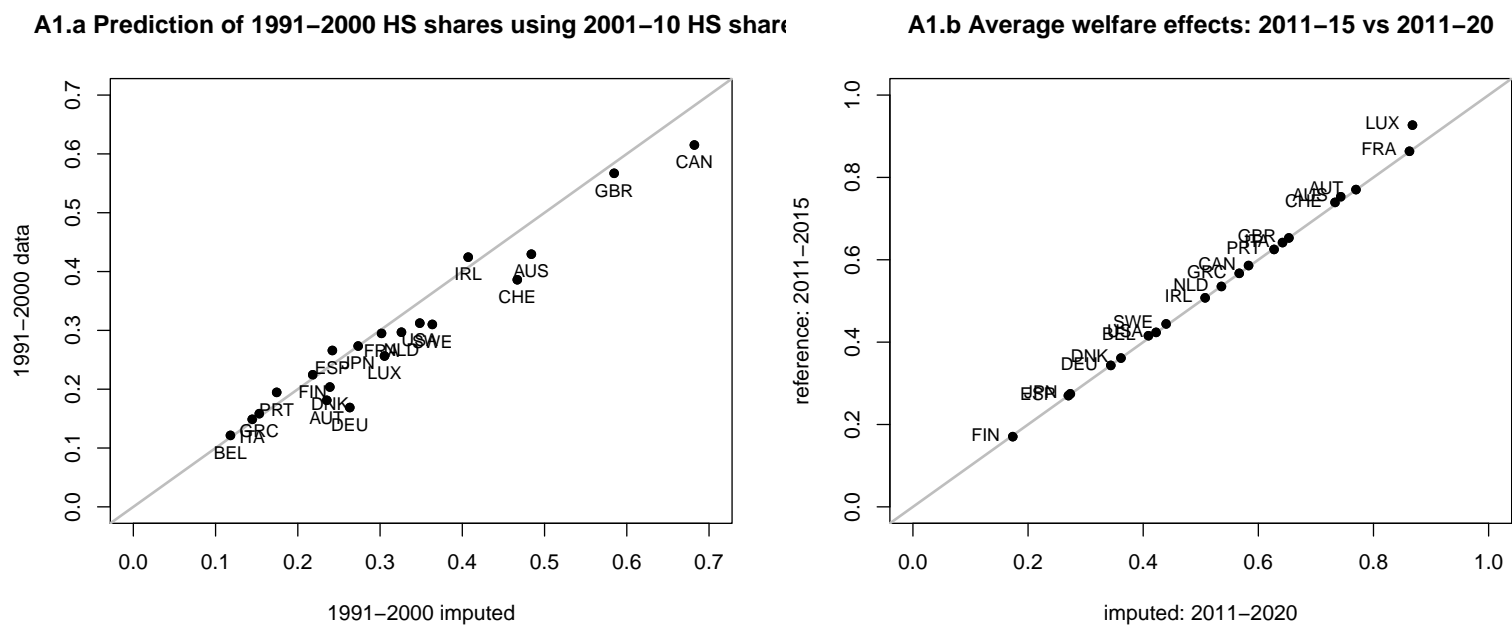

Figure A1: Comparability across immigrant cohorts

Notes. Figure A1 a plots the imputed HS share in the 1991-2000 cohort using the 2001-10 HS shares, while Figure A1 b compares the welfare effects of 2011-15 wave with an imputed 2011-2020 one. 


\section{B Robustness checks}

In this section, we investigate whether the conclusions of the benchmark analysis are robust to the choice of parameters, to the inclusion of technological externalities, to the fiscal rule used to balanced the government budget constraint, and to the characteristics of immigrants. Focusing on the effect of the 2001-2010 wave, we assess the sensitivity of its impact on the average level of real income and on income inequality. Figure B2 depicts the results obtained under nine variants of the benchmark model.

Sensitivity to elasticities. In Figures B2, a and B2, b, we consider alternative levels for three elasticities, namely for the elasticity of substitution between goods in the utility function $(\epsilon=4$ instead of 7), for the elasticity of substitution between immigrant and native workers in production $\left(\sigma_{2}=50\right.$ instead of 20), and for the inverse of the elasticity of labor supply to labor income $(\eta=5$ instead of 10$){ }^{10}$ For these three variants, we recalibrate the TFP $(A)$ and the disutility of labor $(\phi)$ to match observed GDP levels and participation rates in 2010, and simulate the no-migration counterfactual.

Figure B2 a shows that the average welfare impact of immigration is one and a half times greater when the elasticity of substitution between goods equals 4 , and 1.2 times greater when labor market participation rates are more elastic to labor income. Increasing the elasticity of substitution between immigrant and native workers to 50 has a minor impact on our results. In all variants, the correlation with the benchmark results exceeds 0.99. As far as the inequality impact is concerned, results are almost independent on the choice of elasticity (see Figure B2 b). Hence, the welfare effects depicted in Figure 5 are highly robust to the choice of elasticities.

Sensitivity to externalities. In Figures B2 c and B2 d, we account for three TFP externalities. The first one is a schooling externality; it assumes that the elasticity of TFP to the proportion of college graduates in the labor force is equal to 0.3, in line with de la Croix and Docquier (2012) or Aubry et al. (2016). The second one is a diversity externality; it assumes that the semielasticity of TFP to birthplace diversity is equal to 0.2, as in Alesina et al. (2016) or Ortega and Peri (2014). The third one is a diaspora externality which captures the effect of migration on trade and FDI, and the resulting effect of trade and FDI on TFP. Although our model does not account for trade and FDI, we directly model the TFP externality due to the presence of migrant diasporas. A first strand of literature has identified a causal impact of migration on trade and FDI, with respective elasticities of 0.1 and $0.2 \sqrt{11}$ Another strand has identified a causal effect of trade and FDI on TFP, with respective elasticities of 0.3 and 0.01 (see Anderson et al., 2016, Feyrer, 2009). Combining these findings gives an elasticity of TFP to migration of 0.035 . For

\footnotetext{
${ }^{10} \mathrm{An}$ additional robustness check has been run to validate our assumption about identical elasticities of substitution between natives and migrants in both of the skill groups considered. Following Ottaviano and Peri (2012), we set the above-mentioned parameter to 14 in the group of high-school dropouts. We find that the welfare effect for the low-skilled immigrants is more pronounced (the difference with the benchmark is below 1.5 p.p.), while the rest of worker types are unaffected.

${ }^{11}$ On migration and trade, see for example Iranzo and Peri (2009), Felbermayr et al. (2010), Felbermayr and Toubal (2012) and, for studies exploiting natural experiments, Parsons and Vézina (2017) and Steingress (2015). On migration and FDI, see Kugler and Rapoport (2007) and Javorcik et al. (2011).
} 
B1.a Robustness to parameters - average income of natives

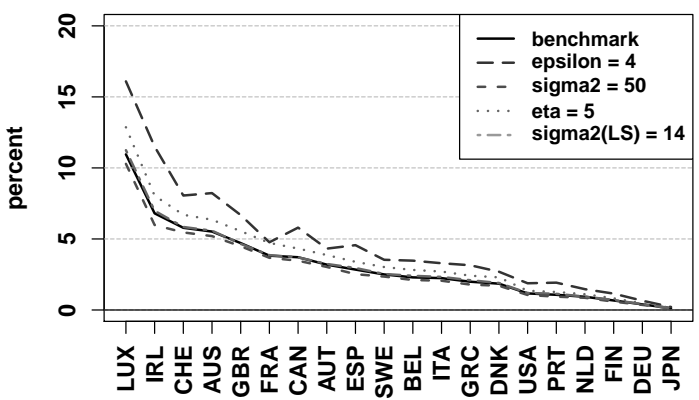

B1.c Robustness to externalities - average income of natives

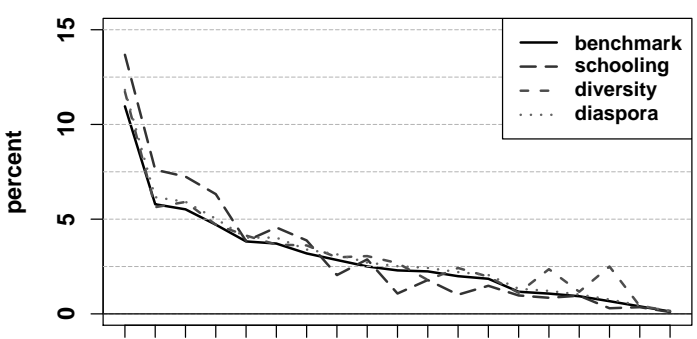

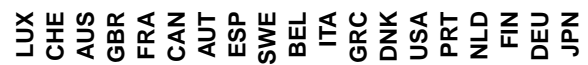

B1.e Robustness to characteristics - average income of native

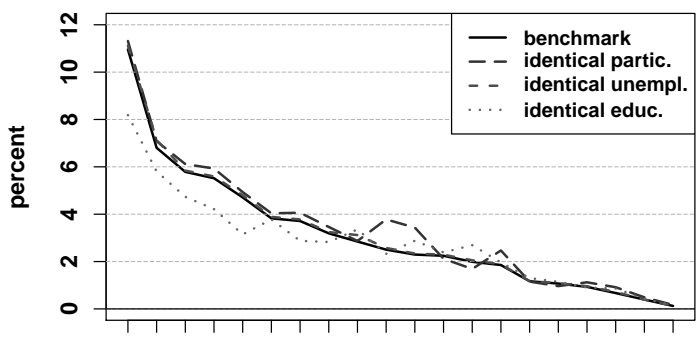

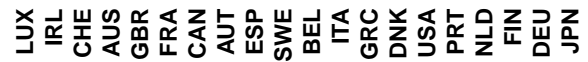

B1.g Robustness to budget - average income of natives

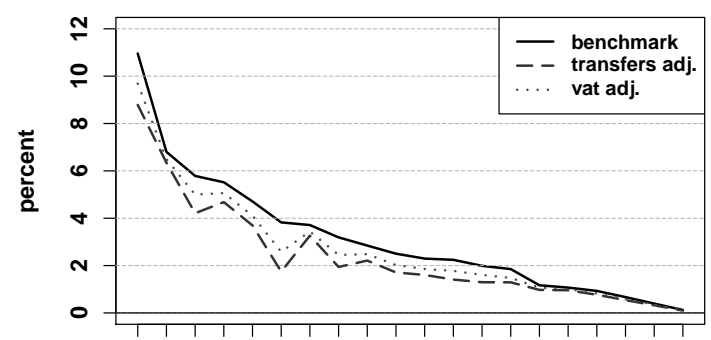

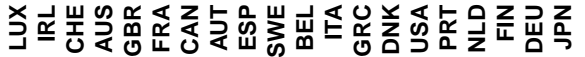

B1.b Robustness to parameters - income differential

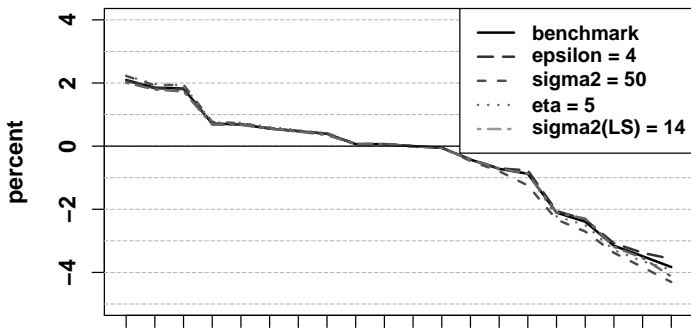

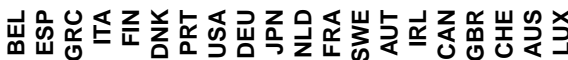

B1.d Robustness to externalities - income differential

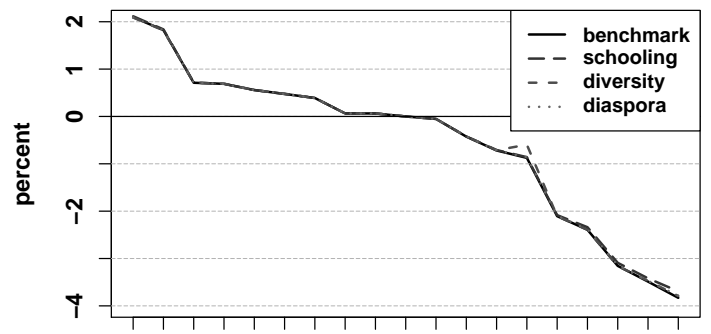

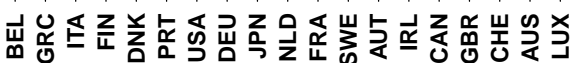

B1.f Robustness to characteristics - income differential

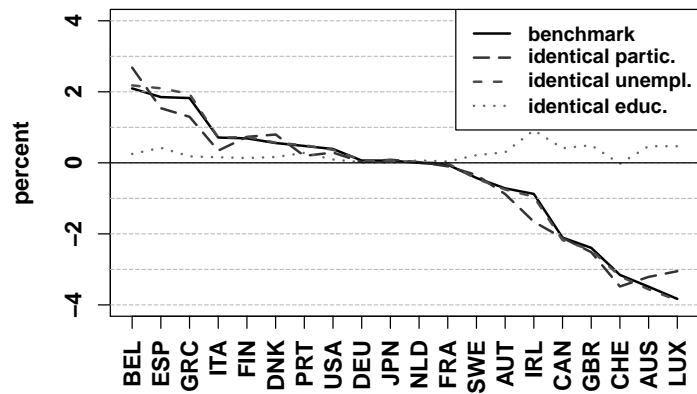

B1.h Robustness to budget - income differential

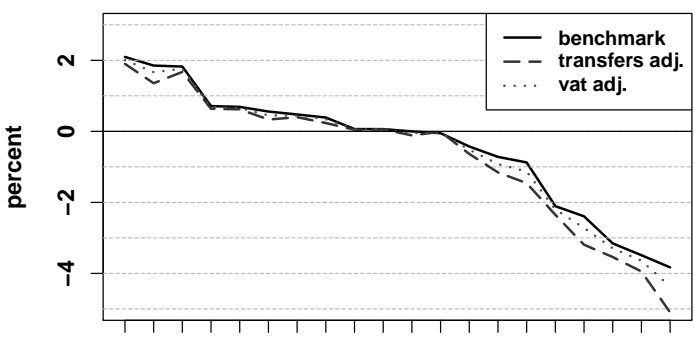

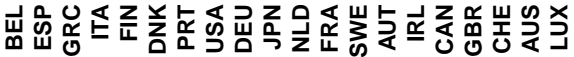

Figure B2: Sensitivity analysis (immigration wave 2000-2010)

Notes. Figure B2 shows the results for 20 selected countries: the 15 members states of the European Union (EU15), the US, Canada, Australia, Switzerland and Japan. The left panels depict the changes in average real wages, while the right panels provide deviations in income differentials between high-skilled and low-skilled. 
these three variants, we calibrate the scale factors of the TFP function to match the GDP levels in 2010, and simulate the no-migration counterfactual.

Figure 6.c shows that the schooling externality significantly increases the gain from immigration in countries attracting college-educated migrants (such as Australia, Luxembourg, the United Kingdom and Switzerland) while it reduces the gain in Spain, Belgium and Greece. Birthplace diversity quantitatively matters only in newer immigration countries such as Ireland, Portugal and Finland. At the estimated elasticity levels, the diaspora externality has negligible effects on the results. Results for inequality are almost independent on the inclusion of externalities (see Figure B2 d). Again, the welfare effects depicted on Figure 5 are highly robust to TFP externalities.

Sensitivity to immigrants' characteristics. In Figures B2, e and B2,f, we consider three alternative distributions of characteristics of immigrant workers. We first assume that all immigrants have the same disutility of labor as natives (same $\phi$ 's). We then assume they have identical unemployment rate as natives (same $u$ 's). Finally, we assume identical skill structures for the immigrant and native populations (same $h$ 's). For these three variants, we simulate the new hypothetical benchmark for 2010 (keeping other parameters constant), and simulate the no-migration counterfactuals.

Figure B2. e shows that the average welfare gain from immigration is highly robust to labor market characteristics of immigrants. Imposing the same disutility of labor (governing participation rates) or the same unemployment rate as native workers marginally affects the results, with the exception of Scandinavian countries and Belgium. Inequality responses are also robust to labor market characteristics. This is in line with the fact that changes in employment rates in the post-crisis period hardly affected the welfare impact of immigration. On the contrary, equalizing immigrants' and natives' levels of schooling reduces the gains from immigration in "selective" countries (Figure B2.e), and neutralizes the inequality responses to immigration (Figure B2,f). This confirms that the level of human capital of immigrants affects the macroeconomic and welfare responses to immigration; the degradation of immigrant's human capital after the crisis is responsible for smaller welfare gains.

Sensitivity to the fiscal rule. In our benchmark model, we assume that the income tax rate adjusts to balance the government budget constraint. We consider two alternative fiscal rules, using the consumption tax rate or the amount of public transfers as the adjustment variable. Figures B2 $\mathrm{g}$ and $\mathrm{B} 2 \mathrm{~h}$ show that the average welfare gain from immigration is highly robust to the fiscal rule. Slightly smaller gains are obtained when public transfers or consumption tax rates are used to adjust the budget. This is because the fiscal gain is now shared between young and old natives. 


\section{Country-specific results and parameters}

Table C1: Calibrated country-specific parameters

\begin{tabular}{l|llllllllllllll}
\hline \hline Country & $\psi$ & $\tau$ & $v$ & $T_{L}^{n}$ & $T_{H}^{n}$ & $T_{L}^{f}$ & $T_{H}^{f}$ & $T_{L R}^{n}$ & $T_{H R}^{n}$ & $T_{L R}^{f}$ & $T_{H R}^{f}$ & $\delta$ & $F C^{n}$ & $E / Y$ \\
\hline AUS & 0,45 & 0,25 & 0,16 & 0,31 & 0,31 & 0,27 & 0,27 & 0,35 & 0,48 & 0,29 & 0,43 & 0,41 & 0,00 & 0,34 \\
AUT & 3,75 & 0,23 & 0,20 & 0,20 & 0,21 & 0,31 & 0,31 & 0,48 & 0,82 & 0,44 & 0,64 & 0,52 & 0,12 & 0,51 \\
BEL & 0,71 & 0,40 & 0,17 & 0,35 & 0,37 & 0,33 & 0,35 & 0,49 & 0,64 & 0,45 & 0,55 & 0,63 & 0,76 & 0,50 \\
CAN & 0,27 & 0,32 & 0,18 & 0,37 & 0,40 & 0,31 & 0,34 & 0,40 & 0,44 & 0,33 & 0,36 & 0,27 & $-0,06$ & 0,41 \\
CHE & 1,79 & 0,20 & 0,09 & 0,12 & 0,16 & 0,18 & 0,23 & 0,32 & 0,36 & 0,38 & 0,40 & 0,53 & 1,95 & 0,33 \\
DEU & 1,88 & 0,24 & 0,14 & 0,17 & 0,21 & 0,25 & 0,30 & 0,36 & 0,44 & 0,45 & 0,52 & 0,42 & $-1,13$ & 0,45 \\
DNK & 0,54 & 0,15 & 0,22 & 0,20 & 0,19 & 0,41 & 0,40 & 0,24 & 0,37 & 0,41 & 0,50 & 0,33 & 0,11 & 0,56 \\
ESP & 2,32 & 0,17 & 0,15 & 0,16 & 0,14 & 0,24 & 0,23 & 0,32 & 0,62 & 0,35 & 0,43 & 0,30 & 0,54 & 0,41 \\
FIN & 2,50 & 0,36 & 0,19 & 0,33 & 0,32 & 0,35 & 0,35 & 0,49 & 0,79 & 0,47 & 0,70 & 0,43 & 0,16 & 0,53 \\
FRA & 0,63 & 0,12 & 0,20 & 0,08 & 0,15 & 0,30 & 0,38 & 0,42 & 0,50 & 0,62 & 0,68 & 0,48 & $-0,52$ & 0,53 \\
GBR & 0,80 & 0,16 & 0,17 & 0,18 & 0,19 & 0,31 & 0,31 & 0,30 & 0,50 & 0,36 & 0,54 & 0,43 & 0,46 & 0,44 \\
GRC & 2,32 & 0,23 & 0,19 & 0,19 & 0,23 & 0,25 & 0,29 & 0,51 & 0,62 & 0,58 & 0,68 & 0,44 & 0,98 & 0,47 \\
IRL & 0,89 & 0,24 & 0,22 & 0,32 & 0,28 & 0,37 & 0,35 & 0,36 & 0,47 & 0,43 & 0,53 & 0,49 & $-0,23$ & 0,50 \\
ITA & 1,16 & 0,20 & 0,18 & 0,15 & 0,23 & 0,25 & 0,33 & 0,47 & 0,54 & 0,55 & 0,62 & 0,29 & 0,98 & 0,48 \\
JPN & 2,00 & 0,15 & 0,12 & 0,11 & 0,11 & 0,20 & 0,20 & 0,32 & 0,42 & 0,36 & 0,45 & 0,22 & 0,00 & 0,37 \\
LUX & 2,95 & 0,47 & 0,16 & 0,47 & 0,52 & 0,26 & 0,31 & 0,86 & 0,89 & 0,41 & 0,43 & 0,46 & 2,02 & 0,44 \\
NLD & 0,71 & 0,33 & 0,17 & 0,34 & 0,34 & 0,26 & 0,32 & 0,43 & 0,65 & 0,32 & 0,51 & 0,23 & 0,40 & 0,46 \\
PRT & 0,80 & 0,22 & 0,20 & 0,23 & 0,21 & 0,27 & 0,27 & 0,48 & 0,95 & 0,44 & 0,58 & 0,23 & 0,52 & 0,46 \\
SWE & 1,25 & 0,13 & 0,27 & 0,20 & 0,20 & 0,34 & 0,33 & 0,37 & 0,55 & 0,47 & 0,60 & 0,38 & 0,20 & 0,52 \\
USA & 1,00 & 0,16 & 0,10 & 0,16 & 0,16 & 0,23 & 0,23 & 0,25 & 0,31 & 0,30 & 0,35 & 0,33 & 0,03 & 0,31 \\
\hline \hline
\end{tabular}

Notes. Table $\mathrm{C} 1$ summarizes the country-specific parameters calibrated using entrepreneurship and fiscal data. $\psi$ stands for the fixed cost of entry, $\tau$ is the income tax rate, $v$ is the consumption tax rate, $T_{s, a}^{o}$ is the transfer send to an individual of origin $o$, age $a$ and skill $s, \delta$ is the share of unemployment benefits in governmental budget in percent, $F C^{n}$ is the net fiscal contribution of immigrants to national budgets, and $E / Y$ is the ratio of governmental expenditures to GDP. 
Table C2: Effects of immigration (Benchmark minus counterfactual as percent of the benchmark)

\begin{tabular}{l|cccccccccc}
\hline \hline 91-00 & ShIm & HCap & Sup & wLN & wHN & wN & inequal & Price & Tax & Empl \\
\hline AUS & $3,13 \%$ & $0,52 \%$ & $36,89 \%$ & $2,61 \%$ & $1,55 \%$ & $2,27 \%$ & $-1,06 \%$ & $-1,10 \%$ & $-3,07 \%$ & $-0,27 \%$ \\
AUT & $8,38 \%$ & $-0,23 \%$ & $40,31 \%$ & $5,87 \%$ & $7,08 \%$ & $6,07 \%$ & $1,21 \%$ & $-2,00 \%$ & $-9,29 \%$ & $-0,29 \%$ \\
BEL & $2,46 \%$ & $-0,19 \%$ & $13,12 \%$ & $1,19 \%$ & $1,46 \%$ & $1,28 \%$ & $0,26 \%$ & $-0,48 \%$ & $-1,67 \%$ & $-0,60 \%$ \\
CAN & $6,59 \%$ & $0,82 \%$ & $57,08 \%$ & $4,20 \%$ & $3,21 \%$ & $3,72 \%$ & $-0,99 \%$ & $-2,02 \%$ & $-3,70 \%$ & $-0,06 \%$ \\
CHE & $13,14 \%$ & $-1,48 \%$ & $75,78 \%$ & $7,08 \%$ & $9,93 \%$ & $7,91 \%$ & $2,85 \%$ & $-3,39 \%$ & $-13,73 \%$ & $-0,46 \%$ \\
DEU & $3,61 \%$ & $-0,52 \%$ & $15,64 \%$ & $0,81 \%$ & $1,66 \%$ & $1,05 \%$ & $0,86 \%$ & $-0,67 \%$ & $-0,70 \%$ & $-0,39 \%$ \\
DNK & $2,15 \%$ & $-0,25 \%$ & $9,97 \%$ & $0,56 \%$ & $0,76 \%$ & $0,62 \%$ & $0,20 \%$ & $-0,28 \%$ & $-0,69 \%$ & $-0,65 \%$ \\
ESP & $2,07 \%$ & $-0,20 \%$ & $10,54 \%$ & $0,71 \%$ & $1,17 \%$ & $0,87 \%$ & $0,46 \%$ & $-0,45 \%$ & $-1,07 \%$ & $-0,23 \%$ \\
FIN & $1,30 \%$ & $-0,18 \%$ & $5,53 \%$ & $0,34 \%$ & $0,62 \%$ & $0,44 \%$ & $0,28 \%$ & $-0,23 \%$ & $-0,41 \%$ & $-0,24 \%$ \\
FRA & $1,16 \%$ & $-0,01 \%$ & $6,16 \%$ & $1,02 \%$ & $1,04 \%$ & $1,03 \%$ & $0,01 \%$ & $-0,22 \%$ & $-1,69 \%$ & $-0,09 \%$ \\
GBR & $1,70 \%$ & $0,36 \%$ & $8,84 \%$ & $1,15 \%$ & $0,71 \%$ & $1,00 \%$ & $-0,44 \%$ & $-0,43 \%$ & $-1,04 \%$ & $-0,09 \%$ \\
GRC & $4,47 \%$ & $-0,53 \%$ & $19,36 \%$ & $1,98 \%$ & $3,59 \%$ & $2,41 \%$ & $1,61 \%$ & $-1,15 \%$ & $-3,42 \%$ & $0,12 \%$ \\
IRL & $1,86 \%$ & $0,36 \%$ & $13,49 \%$ & $1,23 \%$ & $0,73 \%$ & $1,07 \%$ & $-0,50 \%$ & $-0,62 \%$ & $-0,48 \%$ & $0,01 \%$ \\
ITA & $1,66 \%$ & $-0,07 \%$ & $6,61 \%$ & $0,98 \%$ & $1,36 \%$ & $1,04 \%$ & $0,38 \%$ & $-0,43 \%$ & $-1,35 \%$ & $0,06 \%$ \\
JPN & $0,36 \%$ & $-0,05 \%$ & $1,21 \%$ & $0,10 \%$ & $0,17 \%$ & $0,13 \%$ & $0,06 \%$ & $-0,07 \%$ & $-0,12 \%$ & $-0,06 \%$ \\
LUX & $5,11 \%$ & $0,67 \%$ & $62,22 \%$ & $4,77 \%$ & $3,66 \%$ & $4,53 \%$ & $-1,11 \%$ & $-2,09 \%$ & $-4,52 \%$ & $0,16 \%$ \\
NLD & $2,90 \%$ & $-0,20 \%$ & $15,60 \%$ & $0,97 \%$ & $1,28 \%$ & $1,07 \%$ & $0,31 \%$ & $-0,60 \%$ & $-0,95 \%$ & $-0,46 \%$ \\
PRT & $5,13 \%$ & $0,90 \%$ & $21,25 \%$ & $4,36 \%$ & $2,46 \%$ & $4,03 \%$ & $-1,90 \%$ & $-1,71 \%$ & $-4,49 \%$ & $0,59 \%$ \\
SWE & $2,83 \%$ & $-0,01 \%$ & $13,87 \%$ & $1,39 \%$ & $1,39 \%$ & $1,39 \%$ & $0,00 \%$ & $-0,49 \%$ & $-2,64 \%$ & $-0,87 \%$ \\
USA & $3,72 \%$ & $-0,35 \%$ & $24,97 \%$ & $1,05 \%$ & $1,71 \%$ & $1,31 \%$ & $0,66 \%$ & $-0,72 \%$ & $-1,91 \%$ & $0,07 \%$ \\
\hline \hline
\end{tabular}

\begin{tabular}{l|cccccccccc}
\hline \hline 01-10 & ShIm & HCap & Sup & wLN & wHN & wN & inequal & Price & Tax & Empl \\
\hline AUS & $6,72 \%$ & $1,89 \%$ & $74,95 \%$ & $6,63 \%$ & $3,15 \%$ & $5,52 \%$ & $-3,49 \%$ & $-2,49 \%$ & $-8,50 \%$ & $-0,22 \%$ \\
AUT & $3,78 \%$ & $0,44 \%$ & $19,20 \%$ & $3,31 \%$ & $2,59 \%$ & $3,19 \%$ & $-0,72 \%$ & $-0,97 \%$ & $-4,65 \%$ & $-0,10 \%$ \\
BEL & $5,79 \%$ & $-1,66 \%$ & $29,71 \%$ & $1,61 \%$ & $3,71 \%$ & $2,29 \%$ & $2,10 \%$ & $-1,01 \%$ & $-2,99 \%$ & $-1,66 \%$ \\
CAN & $5,82 \%$ & $1,56 \%$ & $50,87 \%$ & $4,74 \%$ & $2,64 \%$ & $3,71 \%$ & $-2,11 \%$ & $-1,86 \%$ & $-3,90 \%$ & $0,02 \%$ \\
CHE & $6,72 \%$ & $2,00 \%$ & $41,88 \%$ & $6,70 \%$ & $3,55 \%$ & $5,79 \%$ & $-3,16 \%$ & $-2,08 \%$ & $-8,85 \%$ & $0,12 \%$ \\
DEU & $1,08 \%$ & $-0,02 \%$ & $4,82 \%$ & $0,38 \%$ & $0,44 \%$ & $0,39 \%$ & $0,06 \%$ & $-0,22 \%$ & $-0,29 \%$ & $-0,10 \%$ \\
DNK & $4,93 \%$ & $-0,57 \%$ & $22,20 \%$ & $1,67 \%$ & $2,23 \%$ & $1,85 \%$ & $0,56 \%$ & $-0,71 \%$ & $-2,45 \%$ & $-1,01 \%$ \\
ESP & $7,04 \%$ & $-0,86 \%$ & $33,87 \%$ & $2,23 \%$ & $4,08 \%$ & $2,84 \%$ & $1,85 \%$ & $-1,51 \%$ & $-3,73 \%$ & $-0,79 \%$ \\
FIN & $2,37 \%$ & $-0,49 \%$ & $9,99 \%$ & $0,41 \%$ & $1,10 \%$ & $0,67 \%$ & $0,69 \%$ & $-0,40 \%$ & $-0,54 \%$ & $-0,50 \%$ \\
FRA & $4,31 \%$ & $0,03 \%$ & $22,16 \%$ & $3,84 \%$ & $3,79 \%$ & $3,82 \%$ & $-0,05 \%$ & $-0,81 \%$ & $-6,33 \%$ & $-0,38 \%$ \\
GBR & $6,14 \%$ & $2,09 \%$ & $30,44 \%$ & $5,50 \%$ & $3,11 \%$ & $4,71 \%$ & $-2,39 \%$ & $-1,76 \%$ & $-6,02 \%$ & $0,24 \%$ \\
GRC & $3,90 \%$ & $-0,64 \%$ & $17,03 \%$ & $1,50 \%$ & $3,32 \%$ & $1,99 \%$ & $1,82 \%$ & $-0,99 \%$ & $-2,90 \%$ & $0,15 \%$ \\
IRL & $13,30 \%$ & $1,38 \%$ & $84,73 \%$ & $7,08 \%$ & $6,21 \%$ & $6,80 \%$ & $-0,88 \%$ & $-4,40 \%$ & $-3,45 \%$ & $0,45 \%$ \\
ITA & $3,33 \%$ & $-0,10 \%$ & $13,07 \%$ & $2,12 \%$ & $2,84 \%$ & $2,24 \%$ & $0,71 \%$ & $-0,89 \%$ & $-3,02 \%$ & $0,20 \%$ \\
JPN & $0,36 \%$ & $-0,05 \%$ & $1,21 \%$ & $0,10 \%$ & $0,17 \%$ & $0,13 \%$ & $0,06 \%$ & $-0,07 \%$ & $-0,12 \%$ & $-0,06 \%$ \\
LUX & $12,86 \%$ & $1,99 \%$ & $137,14 \%$ & $11,79 \%$ & $7,96 \%$ & $10,96 \%$ & $-3,83 \%$ & $-5,06 \%$ & $-11,50 \%$ & $-0,15 \%$ \\
NLD & $2,02 \%$ & $0,02 \%$ & $10,99 \%$ & $0,93 \%$ & $0,93 \%$ & $0,93 \%$ & $0,00 \%$ & $-0,45 \%$ & $-0,98 \%$ & $-0,23 \%$ \\
PRT & $2,63 \%$ & $-0,04 \%$ & $11,18 \%$ & $0,99 \%$ & $1,46 \%$ & $1,07 \%$ & $0,48 \%$ & $-0,72 \%$ & $-0,60 \%$ & $0,20 \%$ \\
SWE & $5,34 \%$ & $0,38 \%$ & $25,39 \%$ & $2,64 \%$ & $2,21 \%$ & $2,50 \%$ & $-0,43 \%$ & $-0,88 \%$ & $-4,68 \%$ & $-1,89 \%$ \\
USA & $3,10 \%$ & $-0,16 \%$ & $20,96 \%$ & $1,01 \%$ & $1,40 \%$ & $1,17 \%$ & $0,39 \%$ & $-0,62 \%$ & $-1,71 \%$ & $0,07 \%$ \\
\hline \hline
\end{tabular}




\begin{tabular}{l|cccccccccc}
\hline \hline $11-15$ & ShIm & HCap & Sup & wLN & wHN & wN & inequal & Price & Tax & Empl \\
\hline AUS & $2,70 \%$ & $0,42 \%$ & $35,09 \%$ & $2,30 \%$ & $1,39 \%$ & $2,01 \%$ & $-0,90 \%$ & $-0,97 \%$ & $-2,51 \%$ & $-0,23 \%$ \\
AUT & $1,80 \%$ & $0,05 \%$ & $9,75 \%$ & $1,38 \%$ & $1,41 \%$ & $1,38 \%$ & $0,04 \%$ & $-0,45 \%$ & $-1,96 \%$ & $-0,05 \%$ \\
BEL & $4,92 \%$ & $-1,03 \%$ & $28,73 \%$ & $1,58 \%$ & $2,90 \%$ & $2,01 \%$ & $1,31 \%$ & $-0,88 \%$ & $-2,33 \%$ & $-1,48 \%$ \\
CAN & $1,79 \%$ & $0,25 \%$ & $17,32 \%$ & $1,20 \%$ & $0,88 \%$ & $1,04 \%$ & $-0,32 \%$ & $-0,56 \%$ & $-0,93 \%$ & $-0,01 \%$ \\
CHE & $2,73 \%$ & $0,18 \%$ & $19,28 \%$ & $2,06 \%$ & $1,85 \%$ & $2,00 \%$ & $-0,21 \%$ & $-0,78 \%$ & $-2,92 \%$ & $-0,03 \%$ \\
DEU & $0,36 \%$ & $-0,04 \%$ & $1,61 \%$ & $0,11 \%$ & $0,16 \%$ & $0,12 \%$ & $0,05 \%$ & $-0,07 \%$ & $-0,09 \%$ & $-0,03 \%$ \\
DNK & $1,02 \%$ & $-0,12 \%$ & $4,90 \%$ & $0,32 \%$ & $0,46 \%$ & $0,37 \%$ & $0,13 \%$ & $-0,15 \%$ & $-0,46 \%$ & $-0,21 \%$ \\
ESP & $-0,68 \%$ & $0,19 \%$ & $-3,50 \%$ & $-0,07 \%$ & $-0,41 \%$ & $-0,18 \%$ & $-0,34 \%$ & $0,13 \%$ & $0,19 \%$ & $0,08 \%$ \\
FIN & $1,26 \%$ & $-0,40 \%$ & $5,53 \%$ & $0,03 \%$ & $0,53 \%$ & $0,22 \%$ & $0,50 \%$ & $-0,19 \%$ & $-0,05 \%$ & $-0,32 \%$ \\
FRA & $0,78 \%$ & $-0,03 \%$ & $4,23 \%$ & $0,66 \%$ & $0,69 \%$ & $0,67 \%$ & $0,03 \%$ & $-0,14 \%$ & $-1,10 \%$ & $-0,07 \%$ \\
GBR & $1,30 \%$ & $0,32 \%$ & $7,05 \%$ & $0,98 \%$ & $0,60 \%$ & $0,85 \%$ & $-0,38 \%$ & $-0,35 \%$ & $-0,92 \%$ & $-0,01 \%$ \\
GRC & $-0,22 \%$ & $0,02 \%$ & $-1,01 \%$ & $-0,11 \%$ & $-0,17 \%$ & $-0,13 \%$ & $-0,07 \%$ & $0,06 \%$ & $0,17 \%$ & $-0,01 \%$ \\
IRL & $0,31 \%$ & $0,04 \%$ & $2,32 \%$ & $0,17 \%$ & $0,13 \%$ & $0,16 \%$ & $-0,03 \%$ & $-0,10 \%$ & $-0,05 \%$ & $0,01 \%$ \\
ITA & $0,00 \%$ & $0,00 \%$ & $0,00 \%$ & $0,00 \%$ & $0,00 \%$ & $0,00 \%$ & $0,00 \%$ & $0,00 \%$ & $0,00 \%$ & $0,00 \%$ \\
JPN & $-0,06 \%$ & $0,01 \%$ & $-0,20 \%$ & $-0,01 \%$ & $-0,03 \%$ & $-0,02 \%$ & $-0,02 \%$ & $0,01 \%$ & $0,01 \%$ & $0,01 \%$ \\
LUX & $9,14 \%$ & $0,52 \%$ & $150,24 \%$ & $8,17 \%$ & $7,06 \%$ & $7,93 \%$ & $-1,11 \%$ & $-3,88 \%$ & $-5,92 \%$ & $-0,10 \%$ \\
NLD & $0,84 \%$ & $0,07 \%$ & $4,73 \%$ & $0,47 \%$ & $0,41 \%$ & $0,45 \%$ & $-0,07 \%$ & $-0,20 \%$ & $-0,51 \%$ & $-0,06 \%$ \\
PRT & $0,72 \%$ & $0,08 \%$ & $3,19 \%$ & $0,48 \%$ & $0,35 \%$ & $0,45 \%$ & $-0,13 \%$ & $-0,22 \%$ & $-0,40 \%$ & $0,07 \%$ \\
SWE & $2,73 \%$ & $-0,17 \%$ & $14,28 \%$ & $1,16 \%$ & $1,29 \%$ & $1,20 \%$ & $0,14 \%$ & $-0,45 \%$ & $-2,13 \%$ & $-0,97 \%$ \\
USA & $1,05 \%$ & $0,01 \%$ & $7,50 \%$ & $0,43 \%$ & $0,47 \%$ & $0,45 \%$ & $0,04 \%$ & $-0,22 \%$ & $-0,63 \%$ & $0,02 \%$ \\
\hline \hline
\end{tabular}

Notes. Table C2 gives the macroeconomic responses to the three migration waves for 20 selected countries: the 15 members states of the European Union (EU15), the US, Canada, Australia, Switzerland and Japan. The first part gives the results for the 1990-2000 wave; the second part gives the results for the 2000-2010 wave; the third part gives the results for the 2010-2015 wave. Columns are labeled as follows: ShIm stands for the change in the share of immigrants, HCap represents the change in the share of tertiary educated in the destination country, Sup refers to the change in the support ratio, $w L N$ and $w H N$ depict the changes in welfare of low-skilled and high-skilled respectively, Inequal presents the percentage difference between $w H N$ and $w L N$, Price is the change in price index, Tax is the change in the income tax rate, Empl is the change in the employment ratio. 